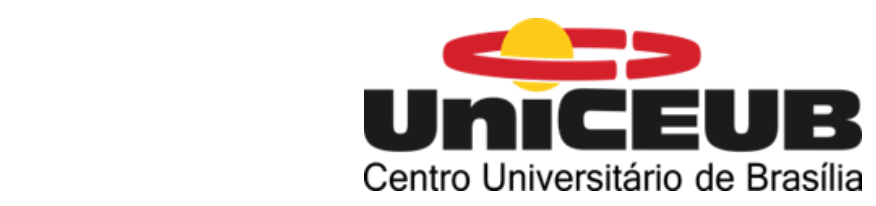

CENTRO UNIVERSITÁRIO DE BRASÍLIA - UnICEUB PROGRAMA DE INICIAÇÃO CIENTÍFICA

JOÃO PAULO ROMUALDO ALARCÃO BERNARDES SARAH MARIA DA SILVA NAPOLEÃO

PESQUISA DE EPÍTOPOS VIRAIS IN SILICO UTILIZANDO BIOINFORMÁTICA NA FABRICAÇÃO DE IMUNOTERÁPICOS DE RELEVÂNCIA CLÍNICA

BRASÍLIA 


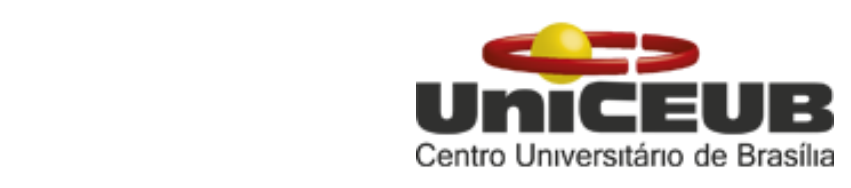

JOÃO PAULO ROMUALDO ALARCÃO BERNARDES

SARAH MARIA DA SILVA NAPOLEÃO

\title{
PESQUISA DE EPÍTOPOS VIRAIS IN SILICO UTILIZANDO BIOINFORMÁTICA NA FABRICAÇÃO DE IMUNOTERÁPICOS DE RELEVÂNCIA CLÍNICA
}

\author{
Relatório final de pesquisa de Iniciação \\ Científica apresentado à Assessoria de Pós- \\ Graduação e Pesquisa. \\ Orientação: Prof. Dra. Kelly Cristina Simi
}

\section{BRASÍLIA}




\section{RESUMO}

A imunologia é a ciência que estuda os mecanismos utilizados pelo nosso organismo no combate a patógenos tais como os vírus Zika e Chikungunya. A bioinformática é uma ciência recente que permite o estudo de diversos processos imunológicos através de softwares de computador. A utilização de ferramentas oriundas da bioinformática possibilita o estudo e predição de estruturas proteicas de diversos patógenos. Esses estudos geralmente estão relacionados com pesquisas de sequências proteicas em banco de dados, para formulação de estruturas tridimensionais de proteínas e predição de epítopos virais que possam gerar uma resposta efetiva do sistema imunológico. Os resultados dessa pesquisa auxiliam no processo de formulação e fabricação de moléculas para utilização em terapias alternativas, como a imunoterapia e desenvolvimento de vacinas, que pudesse ser mais eficiente e específico antes do início de testes em bancada, otimizando assim tempo e recursos. A metodologia utilizada foi aquisição dos epítopos através do banco de dados IEDB, em seguida foi feito reconhecimento das proteínas encontradas pelo site UniProt, foi feita também a análise conformacional das proteínas encontradas e validadas juntamente com o processo de validação in silico dos epítopos encontrados pelo próprio IEDB, a partir desses achados foi possível fazer o rank dos epítopos mais promissores. Foi possível utilizar estratégia de filtragem de dados para proporcionar informações básicas e relevantes para processos como modelagem de proteínas 3D e sugestão de alelos que podem ser utilizados em experimentos in vitro. A pesquisa in silico é um método de pesquisa muito recente e promissor, e se faz necessário o estudo nessa área para auxiliar os métodos in vitro e in vivo da predição de epítopos relevantes para fabricação de vacinas e imunoterápicos.

Palavras-Chave: Bioinformática. Epítopos. Zika. 


\section{AGRADECIMENTOS}

Gostaríamos de agradecer primeiramente a nossa professora orientadora Dra. Kelly Cristina Simi pela oportunidade de desenvolvimento dessa pesquisa, apoio e a confiança ao nos propor esse projeto e também por seus ensinamentos passados durante as disciplinas de imunologia e imunoterapia, o que nos fez ver a magia da imuno em nossas vidas. Agradecemos também ao pessoal da Assessoria de PósGraduação e Pesquisa do UniCEUB, sob a coordenação da Professora Dra. Fernanda Vinhaes juntamente com as colaboradoras da Clara, Olivia e Karine, obrigada pelo apoio e o suporte, e os lembretes de prazos em mais um edital do programa de iniciação cientifica do UniCEUB. Gostaríamos de agradecer também a coordenação do curso de Biomedicina e ao corpo de professores que nos ensinaram não somente disciplinas, mas também a sermos profissionais éticos e responsáveis. Obrigado aos nossos amigos e familiares por sempre nos apoiarem e torcerem por nosso sucesso, vocês são a nossa base e força para continuar sempre. Muito obrigado. 


\section{SUMÁRIO}

1. INTRODUÇÃO

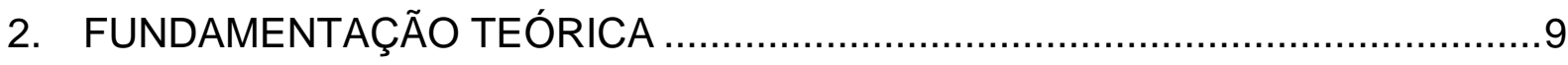

2.1. Caracterização dos vírus Zika e Chikungunya ...........................................

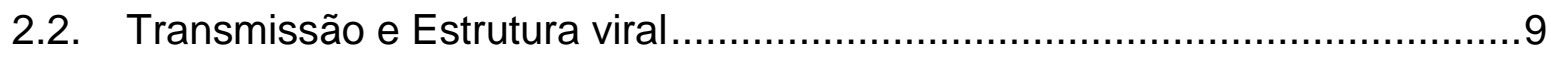

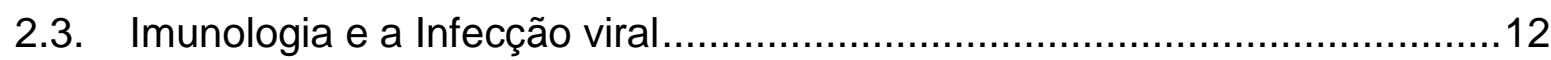

2.4. Imunopatogênese da infecção por ZIKV e CHIKV ....................................13

2.5. Definição de Epítopos e moléculas de HLA ……......................................15

2.6. Contribuição da Bioinformática e de banco de dados no desenvolvimento de

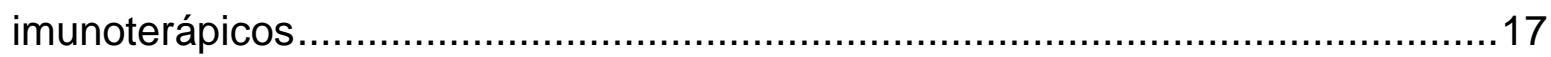

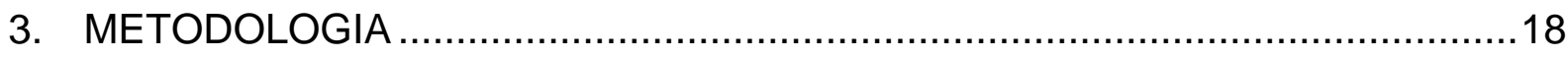

3.1. Obtenção das sequências do epítopos …………...................................18

3.2. BLAST das sequências de epítopos com o banco de dados do UniProt.....20

3.3. Modelagem das sequências proteicas obtidas do BLAST .........................20

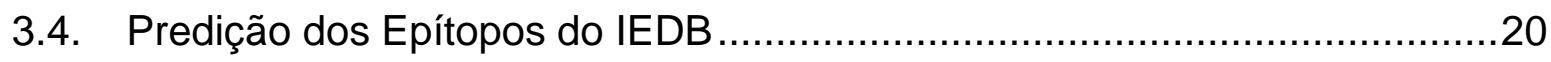

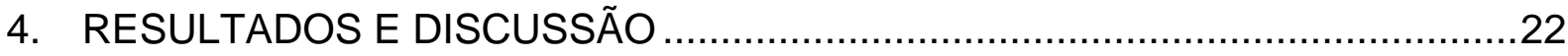

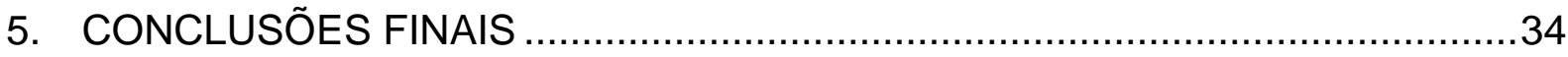

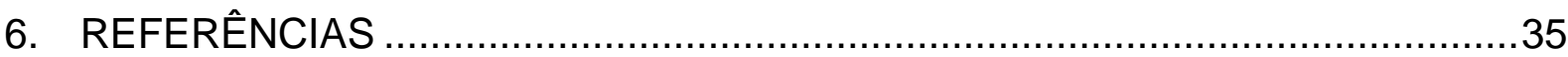




\section{INTRODUÇÃO}

Com o advento das inovações da nova era genômica a bioinformática passou atuar fortemente em pesquisas biológicas e médicas e a produzir número significativo de publicações anuais. Isso se deu ao fato de reunir e trabalhar a interdisciplinaridade entre biologia, ciência da computação, estatística e matemática objetivando analisar dados de sequências biológicas e conteúdo de genomas para predição de funções e estruturas de macromoléculas (RAPLEY, et al., 2015).

Os dados gerados pela Biologia Molecular permitiram o rápido crescimento da bioinformática, com projetos de sequenciamento de genomas e outras tentativas experimentais para determinar a estrutura e a função das moléculas biológicas. $\mathrm{O}$ crescimento dos dados gerou, em contrapartida, a necessidade de se interpretar as informações obtidas (KOZLOVA, et al., 2016).

A bioinformática se aprimorou além da projeção e preenchimento de banco de dados. Procedimentos como pesquisa em bancos de dados genômicos, comparação e análise de sequências fazem parte dos processos de bioinformática atuais. Para aprimorar as informações e pesquisas vários algoritmos computacionais são utilizados, principalmente na busca por sequências de aminoácidos (aa) de determinadas proteínas que tenham algo em comum com peptídeos imunogênicos no que diz respeito a suas regiões de indução de resposta imune celular in vitro (RAPLEY, et al., 2015).

De forma prática, esses algoritmos identificam regiões protéicas que contenham epítopos, além de identificarem também alelos HLA (Human Leukocyte Antigen) que são mais significativos em determinada populações geográficas ou subgrupos em áreas determinadas (MASSY, et al. 2018).Sendo assim, a biologia computacional proporciona um meio de estudar e definir a especificidade da sequência de um epítopo, sendo a maior complexidade, o reconhecimento de padrões que não são codificados pela sequência primária (linear) de uma proteína, mas sim pela sua estrutura terciária, ou seja, tridimensional. Os próprios padrões de aminoácidos nos programas computacionais requerem métodos de reconhecimento de padrões, para assim possibilitar a avaliação direta das sequências proteicas, o que possibilita determinar quais peptídeos podem atuar como epítopos (BREVE, 2010). 
Os epítopos caracterizam-se como sequências formadas por resíduos de aminoácidos relevantes encontrados no antígeno, que atuam nas interações antígenoanticorpo (epítopo-paratopo) (BREVE, 2010). Os anticorpos reconhecem essas sequências com especificidade inconstante (KUNIK e OFRAN, 2013). Ao se formar interação antígeno - anticorpo, ocorrem mudanças estruturais em ambos. Para o antígeno, essas mudanças podem ocasionar em sua neutralização, aumentando as chances de captura e reconhecimento pelo sistema imune (MOYLE e TOTH, 2013). O que de certa forma, permite inferir que os epítopos estão no centro da resposta imune humoral (AVILA, 2013).

Dentro da bioinformática, a área da imunoinformática oferece diversas abordagens para a caracterização in silico dos epítopos, proporcionando o avanço no processo de desenho de peptídeos e moléculas que simulam o epítopo de forma mais prática, direcionada e com menos custos, sendo seu maior desafio a combinação desses métodos computacionais de análise com definição e propriedades importantes para precisão de tais modelos (VITA et al., 2010).

A Bioinformática possibilita o estudo e predição das estruturas proteicas por meio da utilização de métodos computacionais para formulação de estruturas tridimensionais de proteínas fazem parte do grupo de pesquisas atualmente. A descrição de estruturas 3D de uma proteína baseada em sua sequência de aminoácidos ainda é um problema científico fundamental além de um dos desafios da química e da bioinformática (SCHWEDE e PEITSCH, 2008).

Incluído no grupo de microrganismos nocivos a espécie humana, os vírus do gênero Flavivirus dentre eles o Zika vírus (ZIKAV), e do gênero Alphavirus como o Chikungunya (CHIKV) (COLLINS e METZ, 2017),possuem grande relevância para saúde pública principalmente pela sua distribuição em áreas subdesenvolvidas, ou em processo de desenvolvimento como o Brasil, e também pelo seu alto índice de propagação em regiões tropicais (WORLD HEALTH ORGANIZATION, WHO 2017). A transmissão dos arbovírus se dá principalmente por meio de vetores artrópodes e induzem uma infecção celular, levando a um quadro citopatológico (JUNIOR, 2015).

Sendo assim, o objetivo do presente projeto foi pesquisar possíveis epítopos dos vírus Zika e Chikungunya in silico para possibilitar a fabricação de imunoterápicos de relevância clínica, além de analisar epítopos a partir das sequências de possíveis 
antígenos do vírus Zika e Chikungunya, modelar estruturas terciárias dos antígenos dos dois vírus, utilizando modelagem ab initio ou proteínas já moldadas no PDB e validar as estruturas terciárias modeladas dos antígenos dos vírus Zika e Chikungunya.

\subsection{Justificativa}

As arboviroses constituem um grave problema dentro do contexto epidemiológico brasileiro, principalmente pelo ambiente propício a proliferação de vetores, facilitado pelo clima tropical e a falta de profilaxia eficiente pela má gestão da saúde pública. Sendo assim, uma tratativa mais direta precisa ser adotada, evitando surtos e epidemias, para isso o ideal seria a desenvolvimento de imunoterápicos, como vacinas, anticorpos monoclonais, fármacos mais eficientes e com custo benefício mais atraentes.

Apesar do Zika vírus ter uma sintomatologia em sua fase aguda menos agressiva que o Chikungunya, o mesmo apresenta a problemática do acometimento no Sistema Nervoso Central (SNC) como a transmissão vertical que acarreta no desenvolvimento de microcefalia severa em crianças oriundas de mães contaminadas com o vírus no período gestacional, além de em sua fase crônica estar associado a síndrome de Guillain Barré.

Considerando a relevância da bioinformática e dos bancos de dados no trabalho de pesquisas e como instrumento na elaboração de mecanismos funcionais que servem como base de dados para produção de imunoterápicos, o presente trabalho se utiliza desses mesmos bancos de dados voltados para a pesquisa específica de epítopos fundamentais dos vírus Zika e Chikungunya, necessários para a compreensão do mecanismo de ação dos vírus e da velocidade de resposta do sistema imune mais eficazmente. A utilização da bioinformática agiliza a obtenção de conhecimentos científicos básicos, o que é imprescindível para o avanço de novo arsenal biológico no combate e na profilaxia das arboviroses.

Observa-se, portanto, um crescimento na área de bioinformática, proteômica, e no avanço tecnológico em sequenciamento genômico. Esse fato ampliou a possibilidade de se utilizar banco de dados, e analisar os mesmos, para a pesquisa e o reconhecimento de áreas combinantes entre antígenos e anticorpos, combinação de padrões de aminoácidos e desenvolvimento de modelos 3D de proteínas, o que 
faz com que esse trabalho seja bem direcionado e rico em informações. Vale ressaltar que o Brasil vem ganhando destaque internacional em relação ao desenvolvimento de pesquisas voltadas para área de doenças como as arboviroses. Por isso a presente pesquisa visa também agregar conhecimento no âmbito científico brasileiro, enriquecendo a literatura existente em torno do assunto.

\section{FUNDAMENTAÇÃO TEÓRICA}

\subsection{Caracterização dos vírus Zika e Chikungunya}

$\mathrm{O}$ vírus da Chikungunya (CHIKV) pertence à família Togaviridae gênero Alphavirus foi descrito pela primeira vez em 1953 na Tanzânia, durante um surto que foi erroneamente confundido com o vírus da dengue. Desde então a disseminação do vírus se espalhou pela África, Ásia, Europa e em 2013 ocorreu a notificação da transmissão autóctone nas Américas (WHO, 2014). O CHIKV induz uma síndrome febril de início súbito, juntamente com dor articular intensa, cefaleia, mialgia e erupção cutânea (DAS et al., 2010).

O vírus Zika (ZIKV) é um flavivírus causador de quadro febril agudo, e nos últimos anos se disseminou para vários países. O primeiro isolamento do vírus foi realizado em uma fêmea do macaco Rhesus na Floresta Zika, em Uganda em 1947 (NUNES et al., 2015). A infecção pelo vírus é de forma geral branda e raramente evolui para óbito. A sintomatologia consiste em febre, artralgia, conjuntivite não purulenta e erupção com prurido. Cefaleia, mialgia e astenia podem estar associadas. A maior preocupação em relação ao ZIKV se dá pela transmissão vertical, principalmente em função das alterações neurológicas, como a microcefalia em recém-nascidos (OEHLER et al., 2014).

\subsection{Transmissão e Estrutura viral}

Atualmente a transmissão do vírus Zika (ZIKV)aos seres humanos pode ocorrer de duas maneiras gerais: a transmissão vetorial e não-vetorial. A transmissão vetorial caracteriza-se pela picada de vetores artrópodes principalmente do gênero Aedes, já a transmissão não-vetorial se dá pelo contato direto entre indivíduos infectados como por exemplo: transfusão sanguínea, contato materno-fetal e contato sexual (SONG, et 
al., 2017). A transmissão do vírus Chikungunya (CHIKV) é oriunda da picada de mosquitos hematófagos infectados e até o momento nenhuma transmissão nãovetorial foi descrita (REINHOLD et al., 2018).

Em relação a estruturas virais, o ZIKV possui partículas virais envelopadas, esféricas que medem entre 40 a 60 nm de diâmetro. (BRITO \& DONATO, 2017). Além disso o material genético do ZIKV é formado por um genoma de ácido ribonucleico (RNA) de cadeia simples com polaridade positiva, em arranjo icosaédrico, seu capsídeo está envolto por um envelope lipídico derivado da membrana da célula hospedeira. (RELICH \& LOEFELHOLZ, 2017). O genoma do ZIKV possui entorno de 10,8 kb de comprimento, com as regiões 5' e 3' não codantes e consiste em uma única Open Reading Frame (ORFs) que codifica uma grande poliproteína de 3423 aminoácidos formando uma proteína mãe que será clivada em 10 proteínas individuais, que por consequência formarão 03 proteínas estruturais e 07 proteínas não- estruturais, sendo que, as proteínas estruturais formam a partícula infecciosa, as proteínas não estruturais são necessárias para a replicação do genoma viral.(SONG et al.,2017).

Os flavivírus iniciam seu ciclo replicativo com a fixação dos vírions à membrana citoplasmática de uma célula saudável, por um processo geralmente mediado pelas interações entre glicoproteínas da superfície viral e receptores da célula hospedeira (SANLÉS et al., 2017). Para que o processo de adesão e entrada do vírion em uma célula- alvo ocorra é necessário a presença de receptores de entrada e fatores de adesão, que agirão de maneira distintas. Os fatores de adesão retêm as partículas virais na superfície celular até que ocorra a interação com os receptores de entrada. Os receptores de entrada proporcionam interações que resultam na internalização do vírus pela célula (REY, STIASNY \& HEINZ, 2017).

Como os mosquitos vetores possuem a capacidade de inocular o ZIKV no hospedeiro durante o repasto sanguíneo, as células mais propícias a se tornarem alvos iniciais são às da região da derme e epiderme. Estudos observados por Hamel et al. (2015) demonstraram que a entrada do ZIKV e sua replicação em células como fibroblastos, células dendríticas imaturas e queratinócitos principalmente se dá pela ativação de fatores de adesão e de entrada, como a lectina tipo $C$ transmembrana, conhecida como DC-SIGN, e moléculas das famílias TIM e TAM. A DC-SIGN é 
geralmente expressa em algumas subpopulações de macrófagos e células dendríticas imaturas, sua capacidade destaque é de promover a infecção de flavivírus por interação com glicanos $\mathrm{N}$-ligados da proteína de envelope viral (TASSANEETRITHEP et al., 2003; DAVIS et al., 2006).

Os receptores TIM e TAM fazem parte de famílias diferentes de receptores transmembrana e possuem a capacidade de se ligarem a resíduos de fosfatidilserina presentes na membrana do virion. A sua relevância no processo de instalação do vírus no organismo hospedeiro está relacionado com o fato de que a exposição de resíduos de fosfatidilserina por células apoptóticas torna-se um sinal fisiológico de indução da fagocitose, sendo assim, os flavivírus utilizam o mecanismo de mimetismo apoptótico para invadir as células-alvo e manipulam as funções das moléculas TIM e TAM, que são essenciais no reconhecimento de corpos apoptóticos (PEREIRA-LECOIN et al., 2013).

Os alfavírus, como o $\mathrm{CHIKV}$, possuem um genoma constituído de uma molécula de RNA fita simples com polaridade positiva e aproximadamente $12 \mathrm{~kb}$ de comprimento (YAP et al., 2017), além disso, o genoma viral do CHIKV possui duas ORFs, a região 5' é capped ("encapada") e codifica quatro proteínas não estruturais muito importantes no processo de replicação viral e a região 3' que é poliadenilada, responsável por codificar cinco proteínas estruturais essenciais para o processo de entrada do vírus na célula alvo, juntamente com a montagem dos nucleocapsídeos e brotamento de vírus a partir da membrana da célula hospedeira.(SHARMA et. al. 2018). O CHIKV possui um núcleo central com às proteínas do capsídeo organizadas em formato icosaédrico, o nucleocapsídeo é envelopado por uma membrana lipídica derivada da célula hospedeira (LONG et al., 2015).

O ciclo de replicação viral do CHIKV ocorre inicialmente no citoplasma das células hospedeiras, tanto do mosquito quanto dos hospedeiros vertebrados (SOLIGNAT et al., 2009). Os vírus entram na célula alvo por endocitose mediada por clatrinas, os vírions são incluídos em endossomos que promovem ambiente com pH propício para mudanças conformacionais nas proteínas estruturais do envelope viral, o que leva a dissociação das mesmas e facilita a fusão da membrana viral com a membrana plasmática do endossomo da célula infectada (VAN DUIJL-RICHTER et al., 2015; VOSS et al., 2010). 
No final desse processo ocorre a liberação do nucleocapsídeo no citoplasma da célula. As proteínas estruturais são relevantes para a formação de vírions maduros que ocorre na membrana da célula hospedeira, vale ressaltar também que a montagem de novos vírions ocorre através da ligação entre o nucleocapsídeo e o RNA viral e o recrutamento das glicoproteínas do envelope, porém é na membrana da célula que ocorre o brotamento das partículas virais montadas, já no formato icosaédrico (SCHWARTZ; ALBERT, 2010; SOLIGNAT et al., 2009).

\subsection{Imunologia e a Infecção viral}

A imunidade contra infecções virais depende do processo colaborativo das respostas do sistema imune inato e adaptativo, que tem como objetivo final bloquear a infecção, eliminar as células infectadas e produz memória imunológica de longo prazo. De forma geral, a resposta imune inata aos vírus inclui as defesas básicas como às barreiras iniciais como a pele e mucosas juntamente com substâncias químicas produzidas pelas células do epitélio e a barreira microbiologia proporcionada pela microbiota natural, e além dessas, existem às barreiras secundárias da imunidade inata como às células e proteínas solúveis que atuam no controle de proliferação microbiana (ABBAS,LICHTMAN \& PILLAI, 2015).

O processo de resposta se inicia quando as células da imunidade inata, como macrófagos, células dendríticas (DCs) teciduais e neutrófilos chegam ao local da inflamação, às mesmas são acionadas por padrões moleculares associadas a patógenos ou a danos celular (PAMPs e DAMPs), por receptores ligados de reconhecimento de padrões moleculares (PRRs). O processo de reconhecimento de PAMPs virais pelos PRRs culmina na ativação de vias de sinalização bioquímicas, como às das proteínas cinases, que ativam fatores de transcrição que levam a transcrição dos genes de interferon e de citocinas pró-inflamatórias (ABBAS, LICHTMAN \& PILLAI, 2015).

Os interferons do tipo I (IFN-I) são as citocinas principais envolvidas no processo da resposta imune inata durante o curso de uma infecção viral, apesar de diversas outras citocinas e quimiocinas também serem produzidas (SILVA, 2017). Os IFN-I atuam nas células induzindo a inibição da replicação viral, sendo que os IFN-I produzidos nas células infectadas interagem com os receptores IFNAR1 IFNAR2 em 
células vizinhas não infectadas desencadeando ativação de cinases capazes de interagir com o núcleo da célula e estimular a transcrição de genes antivirais (MURPHY, 2014).

Já a resposta imune adaptativa a infecção viral consiste na ação da resposta imune celular, mediada por linfócitos $\mathrm{T}$ junto com a resposta imune humoral, mediada por linfócitos B. Quando confrontada por diferentes estímulos, as células T auxiliares (TCD4+) se dividem em diversos subtipos de linfócitos $T$ auxiliares (Th), como Th1,Th2,Th9,Th17,Th22 e Treg (Th reguladoras) e ThF (Th foliculares), os quais produzem padrões diferentes de citocinas, que por consequência levam a diferentes mecanismos de resposta. Os linfócitos TCD8+, quando ativados, são chamados de células T citotóxicas e possuem a capacidade e eliminar alvo infectados utilizando mecanismos de citotoxicidade (RAPHAEL et al., 2015; ABBAS, LICHTMAN\&PILLAI, 2015).

A resposta imune humoral tem como célula principal os linfócitos $B$, que são células capazes de produzir anticorpos quando ativados, após o reconhecimento da infecção viral e assim evitam a disseminação do vírus ao neutralizarem o vírus os marcando para fagocitose, juntamente com a ativação do sistema complemento e marcação das células infectadas. As células T auxiliares fornecem sinais necessários mediados por moléculas de superfície e ajudam as células B a produzirem anticorpos de alta afinidade, fazerem troca de isotipos de anticorpos e se tornarem células de memória (ABBAS, LICHTMAN \& PILLAI, 2015).

\subsection{Imunopatogênese da infecção por ZIKV e CHIKV}

A maioria dos flavivírus capazes de infectar humanos acabaram desenvolvendo mecanismos para inibir as respostas do IFN do tipo I utilizando antagonismo da sinalização feita por cinases, e assim impedindo que a cascata de respostas oriundas dessa sinalização culmine na deficiência de interferons e citocinas pró- inflamatórias (SILVA, 2017).

Bowen et al. (2017) realizou estudos em células dendríticas humanas que demonstraram a infecção pelo ZIKV não induz forte ativação delas, o que ocasionou também na baixa produção de citocinas pro inflamatórias e de IFN do tipo I o que 
resultou na não produção de proteínas antivirais. Os autores puderam concluir após estudos mais aprofundados que o ZIKV subverte a imunogênicidade das células dendríticas durante a infecção através da evasão das respostas do IFN tipo I, por antagonizar a cascata de fosforilação das STAT1 STAT2, porem a via de sinalização RLRs de outras proteínas inibitórias permanece normal e ativo, o que poderia explicar porque a doença e de certa forma mais amena em humanos.

O ZIKV ativa tanto a resposta adaptativa celular mediada pelos linfócitos TCD4+ e TCD8+(PIERSON \& GRAHAM, 2016), sendo que diversos estudos demonstraram que indivíduos imunocompetentes respondem normalmente contra 0 vírus. Já na resposta imune humoral os anticorpos conseguem se ligar a epítopos localizados nas proteínas estruturais do envelope dos ZIKV (SILVA, 2017).

Em relação ao CHIKV diversos estudos foram realizados tanto em in vivo como in vitro, sendo assim foi possível observar que o tropismo celular inicial do CHIKV é por células aderentes assim como células primarias endoteliais e epiteliais, fibroblastos, macrófagos. Após a picada por mosquito vetor infectado, o vírus replicase na pele do hospedeiro e através do sangue, consegue chegar no fígado e articulações (SCHWARTZ; ALBERT, 2010) passa pelo período de incubação de 2 a 10 dias (WEAVER et al., 2018). O estagio agudo da infecção e marcado por aumento dos componentes da resposta imune celular, o que por consequência leva a ativação das células inatas NK, além disso, macrófagos infectados são induzidos a se diferenciarem em células parecidas com osteoclastos que acabam aumentando a produção de mediadores da artrite como IL-6 e TNF- $\alpha$ (TANABE et al., 2018).

Respostas imunes inatas e adaptativas estão conectadas pela participação das células dendríticas na infecção por CHIKV na apresentação de antígenos. (TANABE et al, 2018) sendo que a resposta adaptativa aparece após uma semana depois que a infecção é resolvida, ocorrendo até mesmo produção de anticorpos anti -CHIKV que tem como alvo as proteínas do envelope viral e levam a remoção do vírus. A resposta imune celular mediada por linfócitos $\mathrm{T}$ também se apresenta eficaz no processo de eliminação do vírus. O problema maior está no quadro cronificado da doença cujo estudos levantam a hipótese de que os macrófagos acabam tornando-se reservatórios do CHIKV além de conseguirem regular o perfil das Th1/Th2 nos tecidos danificados, o que leva a respostas pró- inflamatórias prolongadas (JUNIOR, 2019). 


\subsection{Definição de Epítopos e moléculas de HLA}

O elemento central da resposta humoral, chamados de epítopos, conhecidos também por determinantes antigênicos, são sequências, reconhecidas pelos anticorpos com especificidade variável. formadas pelos resíduos de aminoácidos importantes que fazem parte das interações antígeno-anticorpo dos antígenos. Essa interação provoca mudanças estruturais tanto no antígeno quanto no anticorpo. Com as mudanças, pode ocorrer neutralização do antígeno, o que consequentemente pode facilitar que seja processado pelo sistema imune. Compreender rápida e eficazmente as propriedades dos epítopos pode levar à detecção, ao isolamento e a caracterização das moléculas associadas a diversas enfermidades, quer sejam bacterianas, parasitárias ou virais. Além disso, pode também facilitar o desenvolvimento de anticorpos monoclonais, mimotopos, proteínas quimeras e tantos outros produtos (AVILA, 2013).

Os epítopos podem ser diferenciados de acordo com o tipo celular que os reconhece e processa a proteína de interesse (alvo) como as células dendríticas, macrófagos e linfócitos T e B por meio de apresentação via MHC classe II. Além disso, os epítopos podem ser distinguidos entre lineares ou conformacionais, sendo os lineares organizados de forma linearmente a uma proteína, ou seja, em sua estrutura primária e os conformacionais remetem-se às estruturas secundárias, terciárias e quaternárias das proteínas (PEREIRA, 2018)

Para o célere planejamento de ferramentas de diagnósticos e a produção de vacinas, a medicina necessita debruçar-se minuciosamente sobre o reconhecimento e as propriedades dos epítopos (BREVE, 2010). A polivalência ou multivalência é a presença de múltiplos epítopos idênticos em um antígeno, para que ocorra uma resposta imune eficiente, além dos anticorpos precisarem se ligar ao antígeno, é necessário que haja o desenvolvimento da ativação de diversos mecanismos regulados por células para que o processamento e a apresentação de epítopos sejam diferentes, o que torna possível classificar os epítopos que são reconhecido por linfócitos T e B (KOZLOVA et al, 2016).

Os epítopos dos linfócitos T são apresentados pelas APC's (células apresentadoras de antígenos) ligados as moléculas de MHC (Major Histocompatibility Complex- Complexo principal de Histocompatibilidade).O locus do MHC contém 2 
conjuntos de genes que são extremamente polimórficos, que são os genes do MHC classe I e MHC de classe II, que por sua vez codificam as moléculas MHC de classe I e classe II responsáveis por apresentares os peptídeos antigênicos aos linfócitos T. As proteínas MHC humanas são chamadas também de HLA (Human Leukocyte Antigen- Antígeno Leucocitário Humano) e possuem diversas denominações, os HLA de classe I são denominados HLA-A, HLA-B, HLA-C, já os de classe II são HLA-DP, HLA-DM, HLA-DQ, HLA-DR. O MHC de classe I está presente nas células nucleadas e respondem ao linfócito TCD8+ citotóxico o qual induz apoptose nas células infectadas, já o MHC de classe II está presente nas APCs e respondem ao linfócito TCD4+ auxiliar- Helper que participam ativando as células B (ABBAS, LICHTMAN \& PILLAI, 2015).

O MHC de classe I consegue acomodar epítopos contendo de 8 a 11 aminoácidos enquanto as moléculas de MHC classe II acomodam epítopos que contém de 13 a 17 aminoácidos (KOZLOVA et al., 2016). A região especifica do anticorpo que se liga a um epítopo e chamada de paratopo, que pode ser formado por sequencias variáveis de aminoácidos que se encontram firmes na estrutura do anticorpo, sendo essa particularidade o que permite ao sistema imune reconhecer uma quantidade extensa de antígenos de diversas origens que possam causar o desequilíbrio da homeostase do hospedeiro (BALASUBRAMANIAN et al., 2013).

Os anticorpos reconhecem sequencias especificas organizadas em conformações pontuais tanto como epítopos lineares e conformacionais, o que acaba tornando possível, em teoria, identificar os epítopos de um antígeno quando reveladas todas as suas características críticas, independe do mesmo ser linear ou conformacional. Os epítopos dependem da sua conformação estrutural, por tanto ao identificar um epítopo é extremamente relevante observar os aminoácidos que se ligam ao anticorpo, porem aqueles que não se ligam são importantes para fornecer a conformação adequada a molécula como um todo, de forma a torna-la apta a se ligar ao anticorpo, ou seja, em um epítopo existe aminoácidos que são considerados mais importantes chamados de aminoácidos críticos ou de contato que caso sejam substituídos, alterariam toda a estrutura do epítopo a ponto de torna-lo inapto para ligar-se ao anticorpo. Por esse motivo o passo de identificação dos aminoácidos críticos no epítopo é importante na predição de peptídeos e proteínas voltadas para a produção de anticorpos (TRIER et al., 2012; KOZLOVA, 2016). 


\subsection{Contribuição da Bioinformática e de banco de dados no desenvolvimento de imunoterápicos}

No século XXI a bioinformática se tornou presente em diversos estudos científicos. Para o armazenamento online dessa grande quantidade de informações geradas nas áreas de genoma, transcriptoma e proteoma, foi necessário a criação de bancos de dados. Alguns bancos de dados como o GenBank, Swissprot, PDB (Protein DataBank) e IEDB (Immune Epitope Database and Analysis Resource), são alimentados por informações da comunidade científica. E a cada ano esses bancos de dados aumenta cada vez mais o seu repositório de informações (BREVE, 2010).

Através desses bancos de dados é possível a avaliação de proteínas e possíveis epítopos de diversos patógenos. O sequenciamento de DNA e a modelagem das proteínas, presentes nesses repositórios, otimizou diversos processos dentro de uma pesquisa. A produção de vacinas, o uso de enzimas de restrição, a análise de peptídeos antimicrobianos, a construção de vetores de expressão e diversos outros ensaios, podem ser avaliados in silico (ensaios computacionais) antes de serem avaliados in vitro diminuindo a chance de erro ou resultados não esperados. (KOZLOVA, et al., 2016).

A vacina é um produto farmacêutico com o melhor custo benefício, isso ocorre devido a prevenção de doenças e consequentemente redução da necessidade de tratamento. Ela reduz a mortalidade de uma população diminuindo então a circulação do patógeno. Entretanto, o desenvolvimento de uma vacina que induz a imunidade contra algum patógeno, pode demandar muito recurso e muito tempo. A evolução tecnológica computacional tornou possível a otimização desse processo, através da bioinformática. Algumas ferramentas da bioinformática, possibilitou estudos focados na seleção dos antígenos, na estrutura dos antígenos, nos adjuvantes e carreadores de antígenos. Com uma melhor seleção, a possibilidade de a vacina gerar resultados positivos é maior (MARÍA et al., 2017).

Além de serem utilizados para produção de vacinas, os antígenos são úteis para seleção de anticorpos específicos que podem ser utilizados como imunoterápicos. Atualmente, alguns estudos vêm sendo realizados como esforços para minimizar os impactos que a infecção pelo vírus Zika pode causar nas gestações (GRUBER, 2017). A proposta é utilizar anticorpos monoclonais direcionados para 
epítopos específicos do vírus Zika como forma de prevenir a transmissão do vírus materno-fetal (SAPPARAPU et al., 2016). Contudo, para obtenção de tais anticorpos, faz-se necessário a seleção de epítopos virais mais imunogênicos.

\section{METODOLOGIA}

O fluxograma abaixo (figura 1), descreve as etapas que foram seguidas para realização do experimento. Essa metodologia foi baseada e adaptada de alguns experimentos prévios como de Kozlova et al. (2016) e Breve (2010), pois ambos apresentaram objetivos semelhantes aos propostos neste projeto.

Figura 1: Fluxograma esquemático da metodologia utilizada.

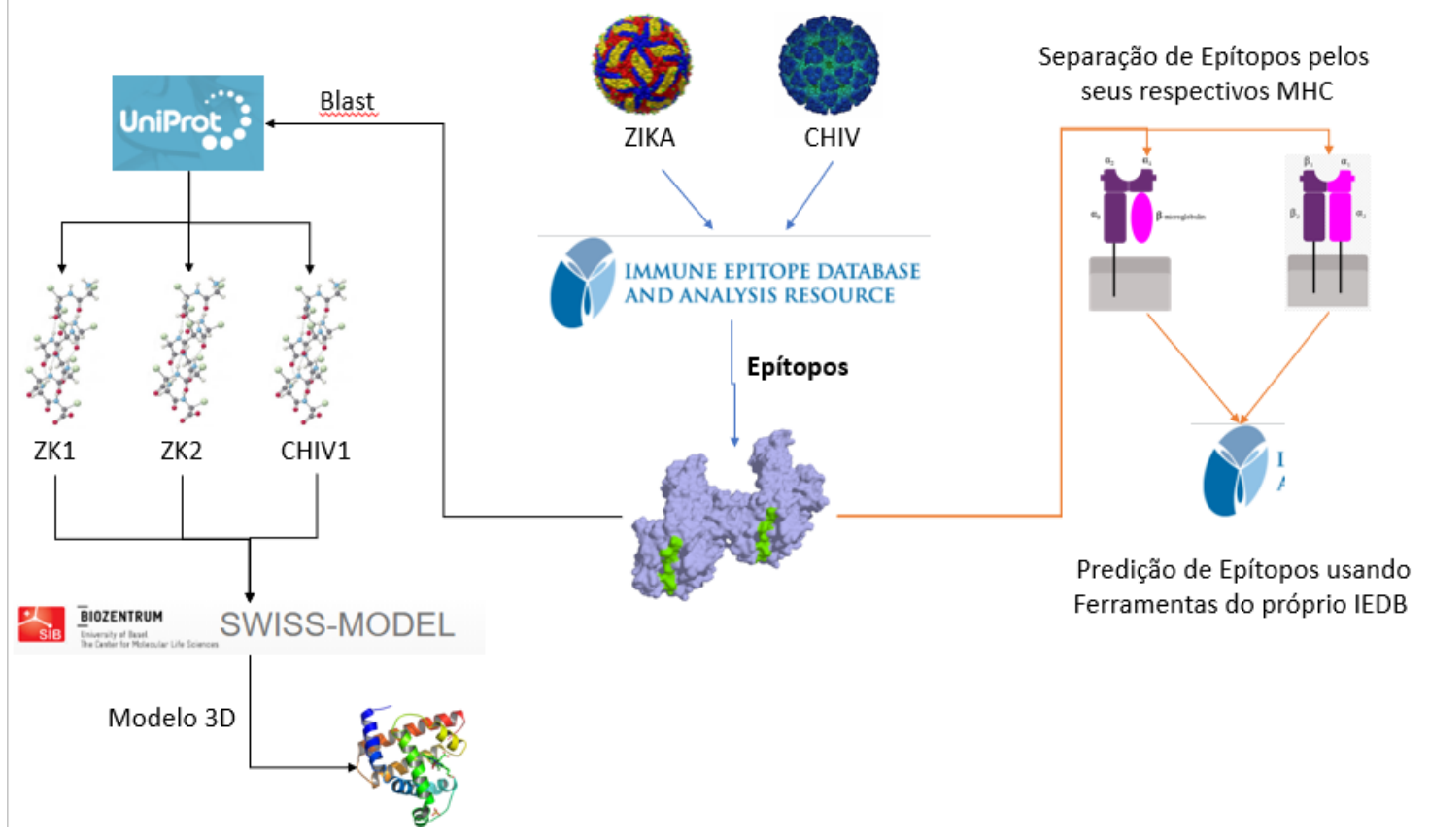

FONTE: Autores, 2019.

\subsection{Obtenção das sequências do epítopos}

As sequências dos epítopos foram retiradas do banco de dados do IEDB (Immune Epitope Database and Analyse Resource). O IEDB presente no domino https://www.iedb.org/, é um banco de dados fundado pelo NIAID (National Institute of Allergy and Infectious Diseases), que possui como objetivo armazenar resultados de estudos com anticorpos e epítopos de células $T$ testados em humanos, primatas não humanos e outras espécies de animais. Além de armazenar as sequências de 
epítopos e informações sobre essas sequências, o IEDB possui ferramentas para análise e predição desses epítopos.

A aquisição das sequências de epítopos do Zika e do Chikungunya, seguiram alguns critérios para melhor qualidade dos dados extraídos. O IEDB fornece as seguintes opções para triagem dos epítopos: Tipo de epítopo, o tipo de ensaio vinculado aquele epítopo, o antígeno, o tipo de $\mathrm{MHC}$ relacionado ao epítopo, a doença e o hospedeiro. A pesquisa foi bem ampla, todos as categorias gerais como tipo epítopo, ensaio, $\mathrm{MCH}$ e doença foram direcionadas para buscar em todo o banco de dados resultado. Já a categoria de hospedeiro foi direcionada para o hospedeiro humano. Os antígenos selecionados para a pesquisa estão descritos na tabela 1. Os achados proeminentes dessa pesquisa ao banco de dados do IEDB foram catalogados utilizando o Microsoft office Excel 365.

Tabela 1:Catálogo de dados filtrados fornecidos pelo IEDB.

\begin{tabular}{|c|c|c|}
\hline Vírus & ID & $\begin{array}{c}\text { Nome no banco de dados } \\
\text { da espécie }\end{array}$ \\
\hline Zika & 64320 & Zika virus \\
\hline Zika & 2316109 & $\begin{array}{c}\text { Zika virus } \\
\text { ZIKV/Human/Cambodia/FSS13 } \\
025 / 2010\end{array}$ \\
\hline Zika & 2043570 & $\begin{array}{c}\text { Zika virus ZIKV/H. } \\
\text { sapiens/FrenchPolynesia/1008 } \\
\text { 7PF/2013 }\end{array}$ \\
\hline Chikungunya & 37124 & Chikungunya virus \\
\hline Chikungunya & 10002197 & Chikungunya virus MY/08/065 \\
\hline Chikungunya & 10001934 & $\begin{array}{l}\text { Chikungunya virus } \\
\text { Singapore/11/2008 }\end{array}$ \\
\hline Chikungunya & 371094 & $\begin{array}{c}\text { Chikungunya virus strain S27- } \\
\text { African prototype }\end{array}$ \\
\hline Chikungunya & 10001997 & $\begin{array}{c}\text { Chikungunya virus strain } \\
\text { LR2006_OPY1 IMT/Reunion } \\
\text { Island/2006 }\end{array}$ \\
\hline
\end{tabular}




\subsection{BLAST das sequências de epítopos com o banco de dados do UniProt.}

As sequências de epítopos que foram catalogadas do IEDB passaram por um Blast utilizando o banco de dados do UniProt. O Blast é um tipo de ferramenta que compara sequências alvos com um banco de dados, para achar um link entre a sequência alvo e qualquer sequência existente no banco de dados. O UniProt registrado no domínio https://www.uniprot.org, é um banco de dados gratuito que armazena informações e sequências de proteínas.

Esse passo foi importante para averiguar se os epítopos retirados do IEDB realmente pertencem a uma proteína dos patógenos pesquisados, e de qual proteína esses epítopos são originados. Após o Blast dos epítopos com o banco de dados do UniProt, as proteínas resultantes do Blast foram separadas e catalogadas em Microsoft Office Excel 365.

\subsection{Modelagem das sequências proteicas obtidas do BLAST.}

As proteínas catalogadas foram posteriormente avaliadas utilizando um programa denominado Swiss-Model registrado no domínio https://swissmodel.expasy.org . Essa ferramenta de bioinformática é um servidor dedicado a fazer a modelagem de proteínas. Esse passo foi incluso para averiguar se as proteínas extraídas do UniProt possuíam uma modelagem 3D válida para critério de inclusão e exclusão da funcionalidade da proteína.

\subsection{Predição dos Epítopos do IEDB}

Após todas as etapas de validação, a ferramenta de predição de epítopos do IEDB foi utilizada para avaliar a qualidade dos epítopos. O software MHC Binding Prediction possui um conjunto de ferramentas que preveem o IC50 dos peptídeos (epítopos) que se ligarão às moléculas específicas de MHC. Entretanto a ligação com a molécula de $M H C$ não significa que as células $T$ serão ativadas e gerarão uma resposta contra o antígeno do epítopo. A ligação com o $\mathrm{MHC}$ significa um bom passo para iniciar pesquisas mais a fundo sobre o epítopo e a reação imune que ele pode gerar ao entrar em contato com as células T do sistema imune. Dentro MHC Binding Prediction existem duas ferramentas a ferramenta destinada a interações moleculares com o $\mathrm{MHC}$ de classe I (MHCl) e a destinada a interações moleculares com o $\mathrm{MHC}$ de classe II (MHCII). 
A ferramenta destinada a $\mathrm{MHCl}$ avaliou a interação entre a sequências de aminoácidos do epítopo e o $\mathrm{MHCl}$. Como o $\mathrm{MHCl}$ é produzido pelos diferentes alelos presentes no sistema antígeno leucocitário humano (HLA), o software utilizou os diferentes alelos para realizar as análises entre a ligação do $\mathrm{MHCl}$ que será produzido e o epítopo. Para tal feito, o software foi programado fazer analise apenas com os alelos de HLA's mais comumente descritas na literatura e presentes na população, dando um total de 27 tipos de alelos que podem ser observados na tabela 2.

Tabela 2: Quadro disponível pelo software relacionado HLA e tamanho dos epítopos.

\begin{tabular}{|c|c|c|}
\hline TIPO DE HLA & HLA SELECIONADOS & TAMANHO DO EPITOPO \\
\hline HLA-A & $\begin{array}{l}\text { HLA-A*01:01 } \\
\text { HLA-A*02:01 } \\
\text { HLA-A*02:03 } \\
\text { HLA-A*02:06 } \\
\text { HLA-A*03:01 } \\
\text { HLA-A*11:01 } \\
\text { HLA-A*23:01 } \\
\text { HLA-A*24:02 } \\
\text { HLA-A*26:01 } \\
\text { HLA-A*30:01 } \\
\text { HLA-A } 30: 02 \\
\text { HLA-A*31:01 } \\
\text { HLA-A*32:01 } \\
\text { HLA-A*33:01 } \\
\text { HLA-A*68:01 } \\
\text { HLA-A*68:02 }\end{array}$ & Peptídeos com 9 a 10 aminoácidos \\
\hline HLA-B & $\begin{array}{l}\text { HLA-B* }{ }^{*} 07: 02 \\
H L A-B^{*} 08: 01 \\
H L A-B^{\star} 15: 01 \\
H L A-B^{\star} 35: 01 \\
H L A-B^{\star} 40: 01 \\
H L A-B^{\star} 44: 02 \\
H L A-B^{*} 44: 03 \\
H L A-B^{\star} 51: 01 \\
H L A-B^{\star} 53: 01 \\
H L A-B^{\star} 57: 01 \\
H L A-B^{\star} 58: 01\end{array}$ & Peptídeos com 9 a 10 aminoácidos \\
\hline
\end{tabular}

A ferramenta destinada a MHCll possui alguns métodos diferentes para a predição de epítopos. Além do método utilizado pela ferramenta $\mathrm{MHCl}$ ela utilizou consenso que combina $N N$-align, SMM-align e métodos de biblioteca combinatória. O $N N$-align é um servidor que gera redes neurais artificiais que possibilitam a análise mais apurada entre receptor e ligante. O SMM-align é uma matriz de alinhamento estabilizada, que faz a avaliação entre o peptídeo e o MHC. Essa matriz utiliza dados 
referenciais de MHC de classe II abrangendo 14 alelos HLA-DR (MHC Humano) e três alelos H2-IA de ratos. Já a biblioteca combinatória, se baseiam em um banco de dados contendo diversos peptídeos, que são utilizados como base para estudar novos peptídeos e suas combinações tridimensional, conforme tabela 3.

Tabela 3: Quadro disponível pelo software relacionado HLA e tamanho dos epítopos

\begin{tabular}{|c|c|c|}
\hline $\begin{array}{l}\text { TIPO DE } \\
\text { HLA }\end{array}$ & HLA SELECIONADOS & TAMANHO DO EPITOPO \\
\hline HLA-DP & 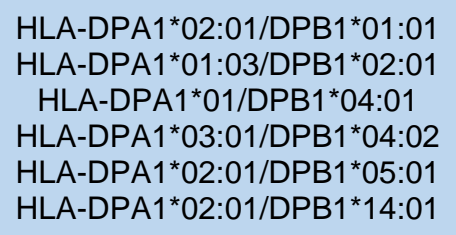 & Peptídeos com 15 a 20 aminoácidos \\
\hline HLA-DQ & $\begin{array}{l}\text { HLA-DQA } 1^{*} 05: 01 / D Q B 1{ }^{*} 02: 01 \\
\text { HLA-DQA }{ }^{*} 05: 01 / D Q B 1{ }^{*} 03: 01 \\
\text { HLA-DQA } 1^{*} 03: 01 / D Q B 1{ }^{*} 03: 02 \\
\text { HLA-DQA } 1{ }^{*} 04: 01 / D Q B 1{ }^{*} 04: 02 \\
\text { HLA-DQA } 1{ }^{*} 01: 01 / D Q B 1{ }^{*} 05: 01 \\
\text { HLA-DQA } 1{ }^{*} 01: 02 / D Q B 1{ }^{*} 06: 02\end{array}$ & Peptídeos com 15 a 20 aminoácidos \\
\hline HLA-DR & 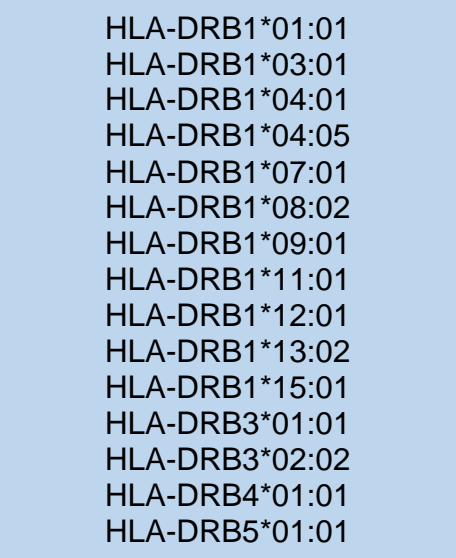 & Peptídeos com 15 a 20 aminoácidos \\
\hline
\end{tabular}

\section{RESULTADOS E DISCUSSÃO}

A extração de epítopos do banco de dados do IEDB resultou em 7 epítopos de Chikungunya para $\mathrm{MHCl}, 0$ epítopos de Chikungunya para MHCII, 26 epítopos de Zika para $\mathrm{MHCl}$ e 66 epítopos de Zika para MHC II. Todas essas sequências foram comparadas com as sequências de proteínas do UniProt. Após o Blast com o banco de dados do UniProt, três proteínas virais foram encontradas duas para Zika e uma para Chikungunya. 
A proteína referente ao Chikungunya é a A0A076VB03_9VIRU (CHIV1). Essa proteína é uma proteína recombinante sintética de uma cepa do Chikungunya denominada LS3. Ela é uma poliproteína estrutural derivada da poliproteína Q8JUX5 (POLS_CHIKS), que possui como função produção do capsídeo viral, glicoproteína E2, proteína $6 k$, glicoproteína E1 e montagem da proteína E3. Todas essas proteínas são importantes para a montagem da estrutura viral.

A primeira proteína do Zika é a Q32ZE1 (ZIKV1) e a segunda é a A0A1D6XWI9 (ZIKV2). As proteínas ZIKV1 e a ZIKV2 são poliproteínas genômicas que possuem como função a montagem de toda a estrutura viral. As estruturas produzidas por essa poliproteína são o capsídeo $C$, peptídeo $P R$, proteína prM, proteína de envelope $M$, proteína de envelope $E$, proteína não estrutural 1, proteína não estrutural $2 A$, proteína não estrutural 2B, proteína não estrutural $4 B$, protease de serina NS3, peptídeo $2 k$ e RNA polimerase NS5.

Essas proteínas foram modeladas utilizando o software Swiss-Model. A modelagem 3D de proteínas vem crescendo nos últimos anos para avaliar a forma $\mathrm{e}$ função das proteínas. A modelagem de uma proteína se baseia nas interações químicas entre os aminoácidos. Entretanto um molde de uma proteína é algo realmente difícil devido as inúmeras interações químicas e os moldes físicos que essas proteínas podem adotar. O Swiss-Model, modelou as três proteínas estudadas, que podem ser visualizadas nas imagens 1 , 2 e 3 . Os moldes 3D possuíam $100 \%$ de identidade com as sequencias das poliproteínas virais. 
Imagem 1: Molde 3D da proteína CHIV1.

\begin{tabular}{|c|}
\hline $\begin{array}{c}\text { Sigla: } \\
\text { CHIV1 }\end{array}$ \\
\hline $\begin{array}{c}\text { Nome registrado no UniProt: } \\
\text { A0A076VB03 (A0A076VB03_9VIRU) }\end{array}$ \\
\hline Site: \\
https://www.uniprot.org/uniprot/A0A076VB03 \\
\hline
\end{tabular}

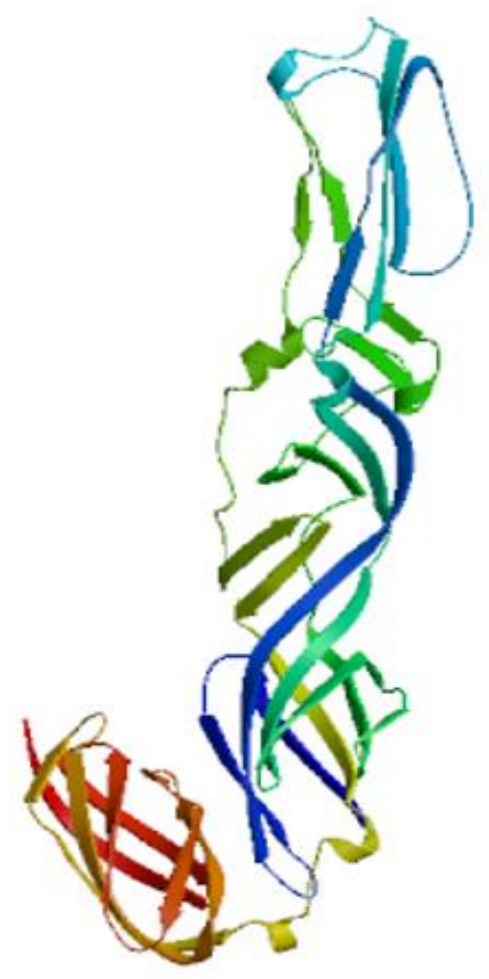

Imagem 2: Molde 3D da proteína ZIKV1.

\begin{tabular}{|c|}
\hline Sigla: \\
ZIKV1 \\
\hline Nome registrado no UniProt: \\
Q32ZE1 (POLG_ZIKV) \\
\hline Site: $\underline{\text { https://www.uniprot.org/uniprot/Q32ZE1 }}$ \\
\hline
\end{tabular}

Fonte: Autores, 2019

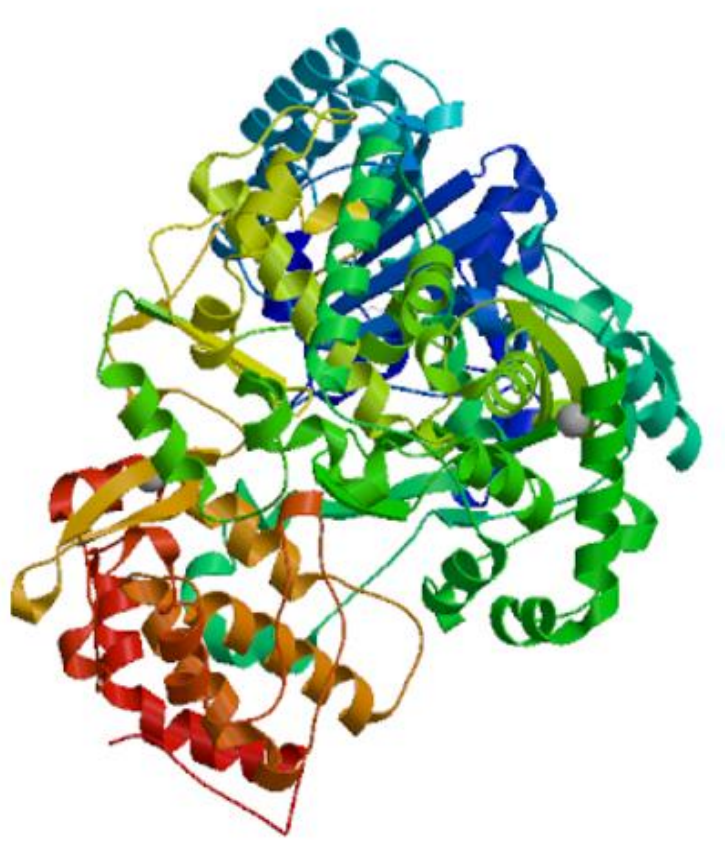


Imagem 3: Molde 3D da proteína ZIKV2.

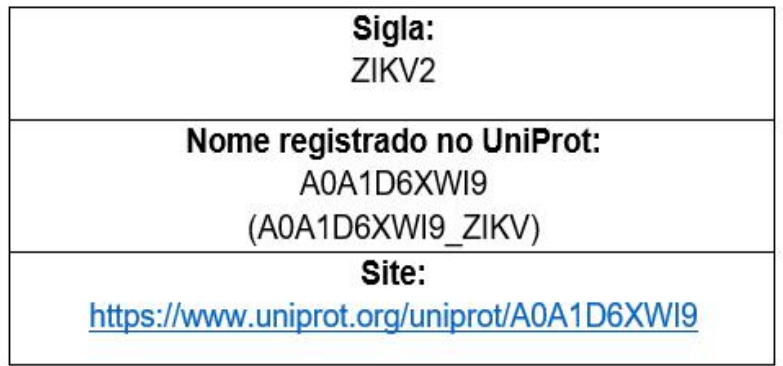

Fonte: Autores, 2019

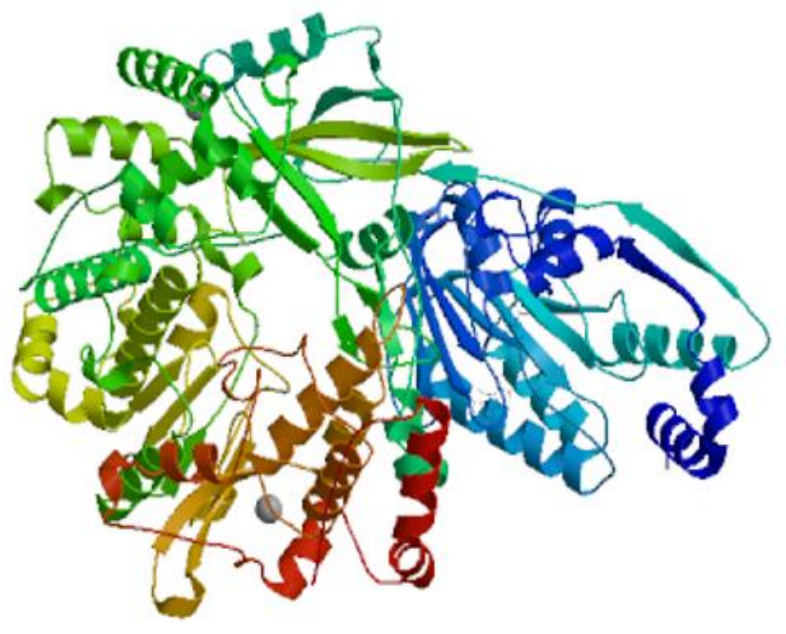

Os epítopos das três poliproteínas, que foram extraídos do IEDB, foram estudados pelos softwares $\mathrm{MHCl}$ e $\mathrm{MHCl}$ fornecido pelo próprio site do IEDB. Os 10 epítopos mais bem pontuados em cada estudo, foram selecionados para os resultados. Foram feitos os seguintes estudos, para $\mathrm{MHCl}$ foi feito estudos separados para epítopos com 9 aminoácidos (aa) e 10aa, para MHCll estudo conjunto para epítopos com 15aa a 20aa. Os $\mathrm{MHCl}$ estão dentro do tamanho esperado conforme a literatura (8-11 aa), já o MHCII está com tamanho um pouco maior que seria entre 13 -17 aa, porem como discorrido antes na fundamentação teórica deste trabalho, a parte relevante do tamanho dos epítopos está na sua região crítica, e que os aminoácidos excedentes podem ser relevantes para a sua estrutura conformacional em uma visão geral.

Kozlova et al. (2016) descreve em seu trabalho que para determinar um epítopo através de predição e análise de dados computacionais torna possível traçar um desenho de uma molécula capaz de substituir um antígeno no processo de produção de anticorpos, e que tais molécula podem ser sintetizadas ou clonadas por um vetor de expressão, inclusive em seu trabalho ele descreve os autores Sivalingam \& Shepherd (2012) que sugerem o tamanho ideal para esse peptídeos que apresentam imunogênicidade seja de 10 a 15 aa.

Nas tabelas 4, 5 e 6 é possível ver o ranking dos epítopos e os alelos aos quais eles foram expostos, o epítopo que foi estudado e o método de análise que o software usou para chegar ao resultado. 
Tabela 4: Ranking dos epítopos e alelos -CHIKV-MHCl.

\begin{tabular}{|c|c|c|c|c|c|c|}
\hline Ranking & Alelo & $\begin{array}{c}\text { Tamanho } \\
\text { (aa) }\end{array}$ & Epítopo & Método de Analise & $\begin{array}{l}\text { ann_IC50 } \\
\text { (nM) }\end{array}$ & $\begin{array}{l}\text { smm_IC } \\
50(n M)\end{array}$ \\
\hline 1 & HLA-A*02:03 & 9 & VMSVGAHTV & Consensus (ann/smm) & 15,33 & 16,9 \\
\hline 2 & HLA-A*02:03 & 9 & ALIPLAALI & Consensus (ann/smm) & 18,12 & 27,16 \\
\hline 3 & HLA-A*02:01 & 9 & ALIPLAALI & $\begin{array}{l}\text { Consensus } \\
\text { (ann/comblib_sidney2008/s } \\
\mathrm{mm} \text { ) }\end{array}$ & 33,11 & 58,9 \\
\hline 4 & HLA-A*02:01 & 9 & VMSVGAHTV & $\begin{array}{l}\text { Consensus } \\
\text { (ann/comblib_sidney2008/s } \\
\mathrm{mm} \text { ) }\end{array}$ & 47,12 & 66,09 \\
\hline 5 & HLA-A*02:06 & 9 & ALIPLAALI & Consensus (ann/smm) & 30,59 & 79,35 \\
\hline 6 & HLA-A*02:06 & 9 & VMSVGAHTV & Consensus (ann/smm) & 145,98 & 70,56 \\
\hline 7 & HLA-A*02:01 & 9 & VLCNCLRLL & $\begin{array}{l}\text { Consensus } \\
\text { (ann/comblib_sidney2008/s } \\
\mathrm{mm} \text { ) }\end{array}$ & 278,63 & 162,6 \\
\hline 8 & HLA-B*35:01 & 9 & QALIPLAAL & $\begin{array}{l}\text { Consensus } \\
\text { (ann/comblib_sidney2008/s } \\
\mathrm{mm} \text { ) }\end{array}$ & 2681,94 & 802,75 \\
\hline 9 & HLA-A*32:01 & 9 & ALIPLAALI & $\begin{array}{l}\text { Consensus } \\
\text { (ann/comblib_sidney2008/s } \\
\mathrm{mm} \text { ) }\end{array}$ & 3581,12 & 502,27 \\
\hline 10 & HLA-A $* 30: 02$ & 9 & VMSVGAHTV & Consensus (ann/smm) & 1047,11 & 971,54 \\
\hline 1 & HLA-A*02:03 & 10 & TLAFLAVMSV & Consensus (ann/smm) & 11,63 & 17,03 \\
\hline 2 & HLA-A*02:01 & 10 & TLAFLAVMSV & Consensus (ann/smm) & 42,58 & 41,64 \\
\hline 3 & HLA-A*02:03 & 10 & ALIPLAALIV & Consensus (ann/smm) & 34,08 & 28,14 \\
\hline 4 & HLA-A*02:01 & 10 & ALIPLAALIV & Consensus (ann/smm) & 54,53 & 81,19 \\
\hline 5 & HLA-A*02:06 & 10 & ALIPLAALIV & Consensus (ann/smm) & 65,25 & 127,91 \\
\hline 6 & HLA-A*68:02 & 10 & TLAFLAVMSV & Consensus (ann/smm) & 91,92 & 110,74 \\
\hline 7 & HLA-A*02:01 & 10 & RLLPCCCKTL & Consensus (ann/smm) & 135,26 & 247,45 \\
\hline 8 & HLA-A*02:06 & 10 & TLAFLAVMSV & Consensus (ann/smm) & 389,54 & 242,61 \\
\hline 9 & HLA-A*02:03 & 10 & RLLPCCCKTL & Consensus (ann/smm) & 605,2 & 132,82 \\
\hline 10 & HLA-B*15:01 & 10 & RLLPCCCKTL & Consensus (ann/smm) & 2030,77 & 114,88 \\
\hline
\end{tabular}


Tabela 5: Ranking dos epítopos e alelos- ZIKV-MHCI

\begin{tabular}{|c|c|c|c|c|c|c|}
\hline Ranking & Alelo & $\begin{array}{c}\text { Tamanho } \\
\text { (aa) }\end{array}$ & Epítopo & Método de Analise & $\begin{array}{c}\text { ann_IC50 } \\
\text { (nM) }\end{array}$ & $\begin{array}{l}\text { smm_IC } \\
50(n M)\end{array}$ \\
\hline 1 & HLA-A*01:01 & 9 & GLDFSDLYY & Consensus (ann/smm) & 5,47 & 110,8 \\
\hline 2 & HI A-B*07.02 & 9 & TPYGOORYF & $\begin{array}{l}\text { Consensus } \\
\text { (ann/comblib_sidney200 } \\
\text { (a/cmm) }\end{array}$ & 13477 & 18151 \\
\hline 3 & HLA-B*08:01 & 9 & VLKPRWMDA & $\begin{array}{l}\text { Consensus } \\
\text { (ann/comblib_sidney200 } \\
8 / \text { smm) }\end{array}$ & 222,4 & 284,15 \\
\hline 4 & HLA-B*53:01 & 9 & TPYGQQRVF & $\begin{array}{l}\text { Consensus } \\
\text { (ann/comblib_sidney200 } \\
\text { 8/smm) }\end{array}$ & 163,92 & 382,72 \\
\hline 5 & HLA-B*35:01 & 9 & TPYGQQRVF & $\begin{array}{l}\text { Consensus } \\
\text { (ann/comblib_sidney200 } \\
\text { 8/smm) }\end{array}$ & 97,74 & 85,82 \\
\hline 6 & HLA-A*30:02 & 9 & GLDFSDLYY & Consensus (ann/smm) & 781,89 & 622,96 \\
\hline 7 & HLA-B*51:01 & 9 & TPYGQQRVF & $\begin{array}{l}\text { Consensus } \\
\text { (ann/comblib_sidney200 } \\
\text { 8/smm) }\end{array}$ & 2564,87 & 3561,48 \\
\hline 8 & HLA-A*30:01 & 9 & VLKPRWMDA & $\begin{array}{l}\text { Consensus } \\
\text { (ann/comblib_sidney200 } \\
\text { 8/smm) }\end{array}$ & 184,17 & 237,12 \\
\hline 9 & HLA-A*03:01 & 9 & GLDFSDLYY & Consensus (ann/smm) & 1670,29 & 1215,63 \\
\hline 10 & HLA-A*02:03 & 9 & VLKPRWMDA & Consensus (ann/smm) & 312,57 & 212,79 \\
\hline 1 & HLA-B*07:02 & 10 & APTRVVAAEM & Consensus (ann/smm) & 11,26 & 16,14 \\
\hline 2 & HLA-B*40:01 & 10 & TEQRKTFVEL & Consensus (ann/smm) & 86,09 & 92,26 \\
\hline 3 & HLA-A*68:01 & 10 & SIQPENLEYR & Consensus (ann/smm) & 115,62 & 72,28 \\
\hline 4 & HLA-B*15:01 & 10 & CLALGGVMIF & Consensus (ann/smm) & 281,11 & 14,87 \\
\hline 5 & HLA-A*31:01 & 10 & SIQPENLEYR & Consensus (ann/smm) & 123,22 & 102,19 \\
\hline 6 & HLA-A*11:01 & 10 & SIQPENLEYR & Consensus (ann/smm) & 74,75 & 292,31 \\
\hline 7 & HLA-B*35:01 & 10 & APTRVVAAEM & Consensus (ann/smm) & 1371,07 & 758,4 \\
\hline 8 & HLA-B*53:01 & 10 & CLALGGVMIF & Consensus (ann/smm) & 949,29 & 1357,81 \\
\hline 9 & & & WDFGSVGGA & & & \\
\hline & HLA-B*40:01 & 10 & $\mathrm{~L}$ & Consensus (ann/smm) & 3187,56 & 403,67 \\
\hline 10 & HLA-B*08:01 & 10 & TEQRKTFVEL & Consensus (ann/smm) & 2677,33 & 791,81 \\
\hline
\end{tabular}


Tabela 6: Ranking dos epítopos e alelos do ZIKV- MHCII

\begin{tabular}{|c|c|c|c|c|c|c|}
\hline Ranking & Alelo & $\begin{array}{l}\text { Tamanho } \\
\text { (aa) }\end{array}$ & Epítopo & Método de Analise & $\begin{array}{c}\text { smm_align } \\
\text { _IC50 } \\
\text { (nM) }\end{array}$ & $\begin{array}{c}\text { nn_alig } \\
\text { n_IC50( } \\
\text { nM) }\end{array}$ \\
\hline 1 & $\begin{array}{l}\text { HLA- } \\
\text { DRB3*02:02 }\end{array}$ & 15 & $\begin{array}{l}\text { IKKFKKDLAA } \\
\text { MLRII }\end{array}$ & NetMHCIIpan* & 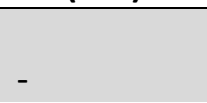 & - \\
\hline 2 & $\begin{array}{l}\text { HLA- } \\
\text { DRB3*01:01 }\end{array}$ & 15 & $\begin{array}{l}\text { KMMLELDP } \\
\text { PFGDSYI }\end{array}$ & $\begin{array}{l}\text { Consensus } \\
\text { (comb.lib./smm/nn) }\end{array}$ & 673 & 83,1 \\
\hline 3 & $\begin{array}{l}\text { HLA- } \\
\text { DPA1*01:03/D } \\
\text { PB1*02:01 }\end{array}$ & 15 & $\begin{array}{l}\text { LDFSDLYYLT } \\
\text { MNNKH }\end{array}$ & $\begin{array}{l}\text { Consensus } \\
\text { (comb.lib./smm/nn) }\end{array}$ & 98 & 20 \\
\hline 4 & $\begin{array}{l}\text { HLA- } \\
\text { DRB1*08:02 }\end{array}$ & 15 & $\begin{array}{l}\text { AAMLRIINA } \\
\text { RKEKKR }\end{array}$ & $\begin{array}{l}\text { Consensus } \\
\text { (smm/nn/sturniolo) }\end{array}$ & 146 & 21,9 \\
\hline 5 & $\begin{array}{l}\text { HLA- } \\
\text { DPA }{ }^{*} 01: 03 / \mathrm{D} \\
\text { PB1*02:01 }\end{array}$ & 15 & $\begin{array}{l}\text { RAIWYMWL } \\
\text { GARFLEF }\end{array}$ & $\begin{array}{l}\text { Consensus } \\
\text { (comb.lib./smm/nn) }\end{array}$ & 11 & 3 \\
\hline 6 & $\begin{array}{l}\text { HLA- } \\
\text { DRB1*11:01 }\end{array}$ & 15 & $\begin{array}{l}\text { SPFGGLKRLP } \\
\text { AGLLL }\end{array}$ & $\begin{array}{l}\text { Consensus } \\
\text { (smm/nn/sturniolo) }\end{array}$ & 11 & 14 \\
\hline 7 & $\begin{array}{l}\text { HLA- } \\
\text { DRB1*11:01 }\end{array}$ & 15 & $\begin{array}{l}\text { VARVSPFGG } \\
\text { LKRLPA }\end{array}$ & $\begin{array}{l}\text { Consensus } \\
\text { (smm/nn/sturniolo) }\end{array}$ & 13 & 31,4 \\
\hline 8 & $\begin{array}{l}\text { HLA- } \\
\text { DRB5*01:01 }\end{array}$ & 15 & $\begin{array}{l}\text { HGPIRMVLA } \\
\text { ILAFLR }\end{array}$ & $\begin{array}{l}\text { Consensus } \\
\text { (smm/nn/sturniolo) }\end{array}$ & 24 & 42,4 \\
\hline 9 & $\begin{array}{l}\text { HLA- } \\
\text { DPA1*01/DPB1 } \\
{ }^{*} 04: 01\end{array}$ & 15 & $\begin{array}{l}\text { RAIWYMWL } \\
\text { GARFLEF }\end{array}$ & $\begin{array}{l}\text { Consensus } \\
\text { (comb.lib./smm/nn) }\end{array}$ & 20 & 4,9 \\
\hline 10 & $\begin{array}{l}\text { HLA- } \\
\text { DRB1*09:01 }\end{array}$ & 15 & $\begin{array}{l}\text { IKKFKKDLAA } \\
\text { MLRII }\end{array}$ & $\begin{array}{l}\text { Consensus } \\
\text { (comb.lib./smm/nn) }\end{array}$ & 36 & 10,7 \\
\hline
\end{tabular}

Os softwares do $\mathrm{MHCl}$ e $\mathrm{MHCll}$ geram um rank preditivo e um rank percentual após a análise do alelo de HLA e o epítopo alvo.

O rank de afinidade preditiva é baseado na unidade IC50nM. Sendo assim, epítopos que apresentam um rank preditivo baixo, significa que eles possuem uma alta afinidade de interação com as moléculas de $\mathrm{MHC}$ e consequentemente apresentam maior chance de ser reconhecida pelo sistema imunológico. A nível comparativo, peptídeos que apresentam valores de IC50 <50nM são considerados de alta afinidade, $<500 \mathrm{nM}$ são considerados de afinidade intermediaria e $<5000 \mathrm{nM}$ são considerados baixa afinidade. Grande parte dos epítopos possuem de forma geral, afinidade alta ou intermediaria, poucos epítopos possuem baixa afinidade. Os gráficos 1,2 e 3 demostram o rank preditivo em IC50nM dos alelos encontrados. 
Gráfico 1: Demonstração do Rank Preditivos em IC50nM dos alelos encontrados para o CHIKV-MCHI. (A) com 9 aminoácidos e (B) com 10 aminoácidos

\section{Chikungunya MHCI (9aa)}

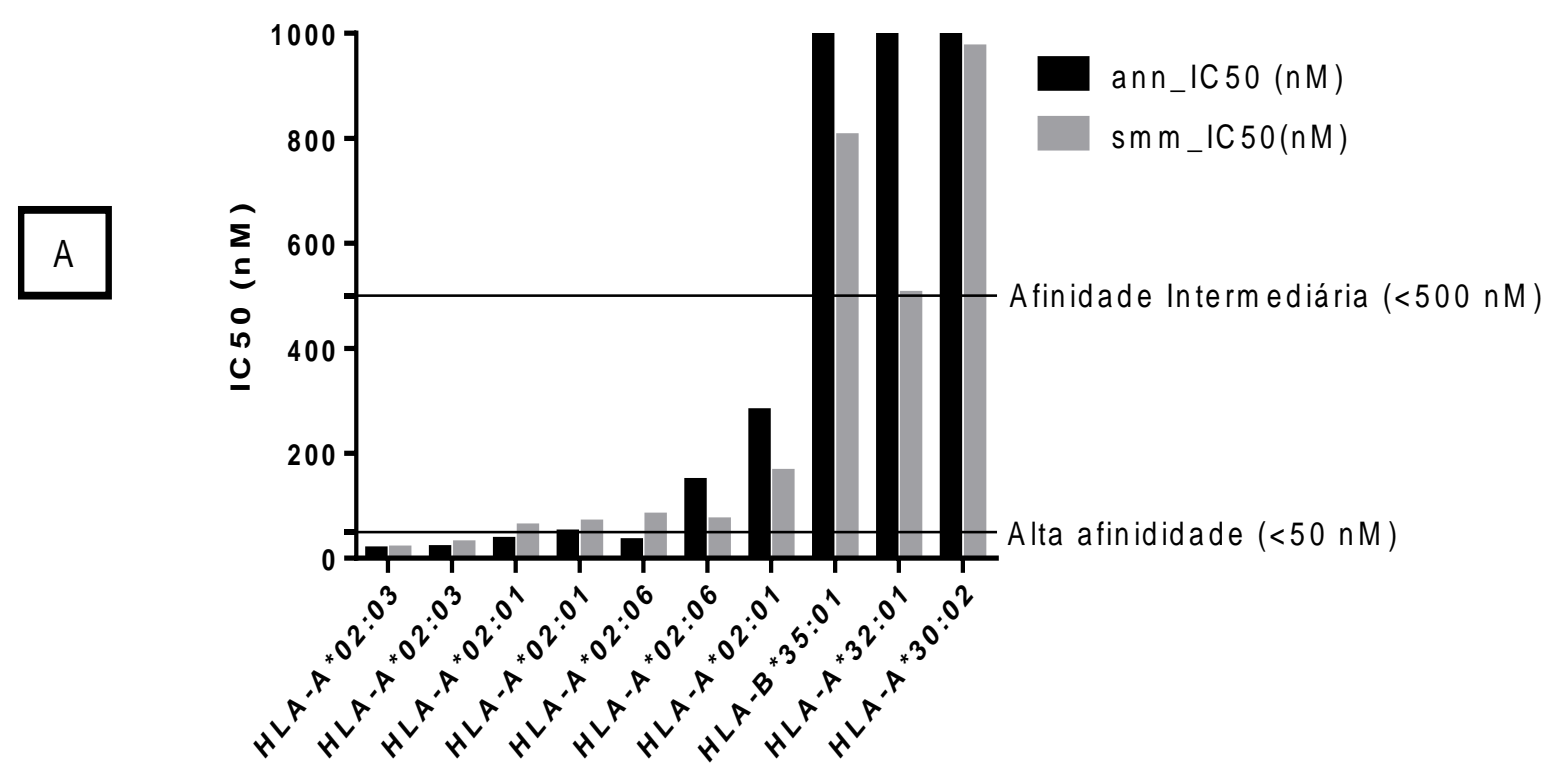

Chikungunya MHCI (10aa)

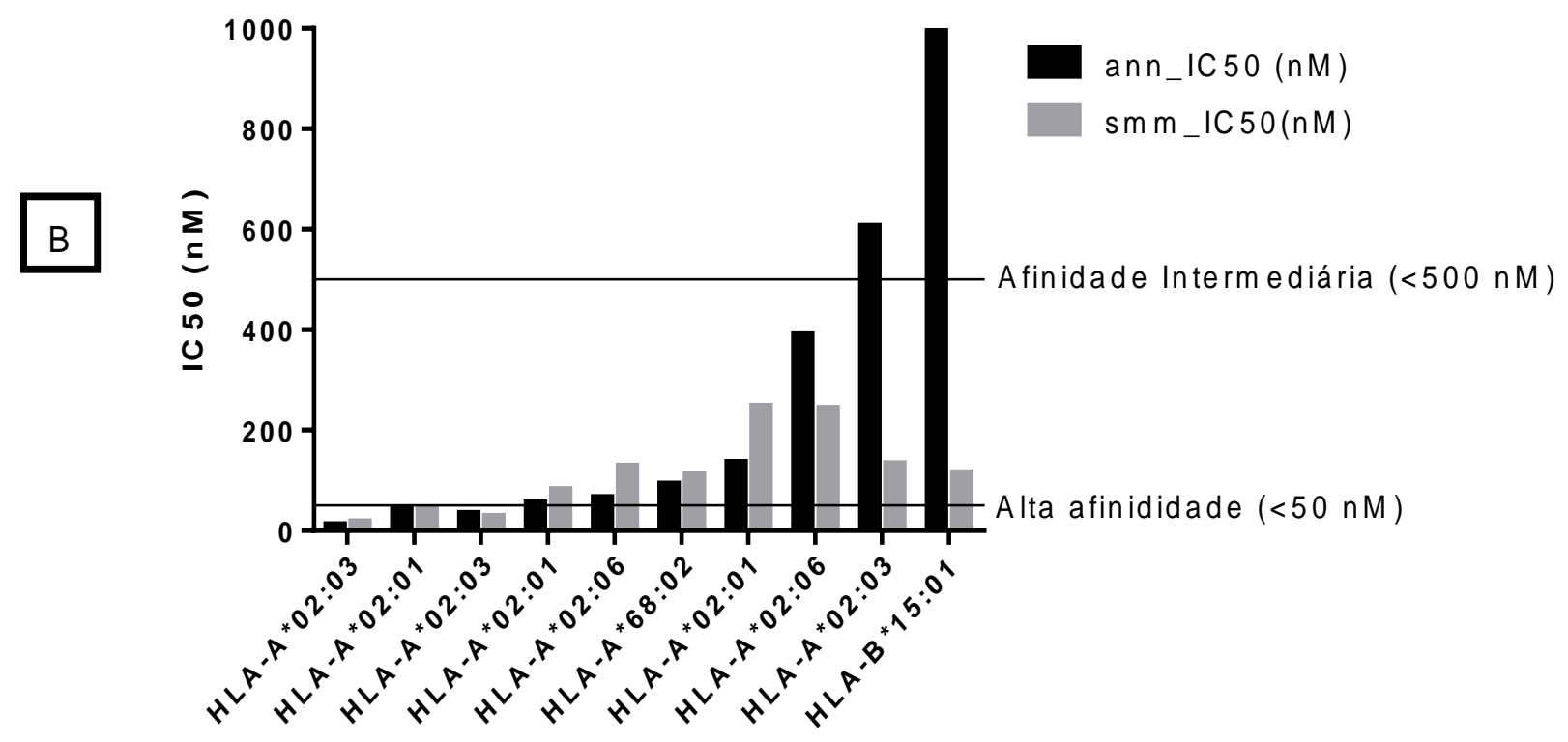


Gráfico 2: Demonstração do Rank Preditivos em IC50nM dos alelos encontrados para o ZIKV-MCHI. (A) com 9 aminoácidos e (B) com 10 aminoácidos

Zika MHCI (9aa)

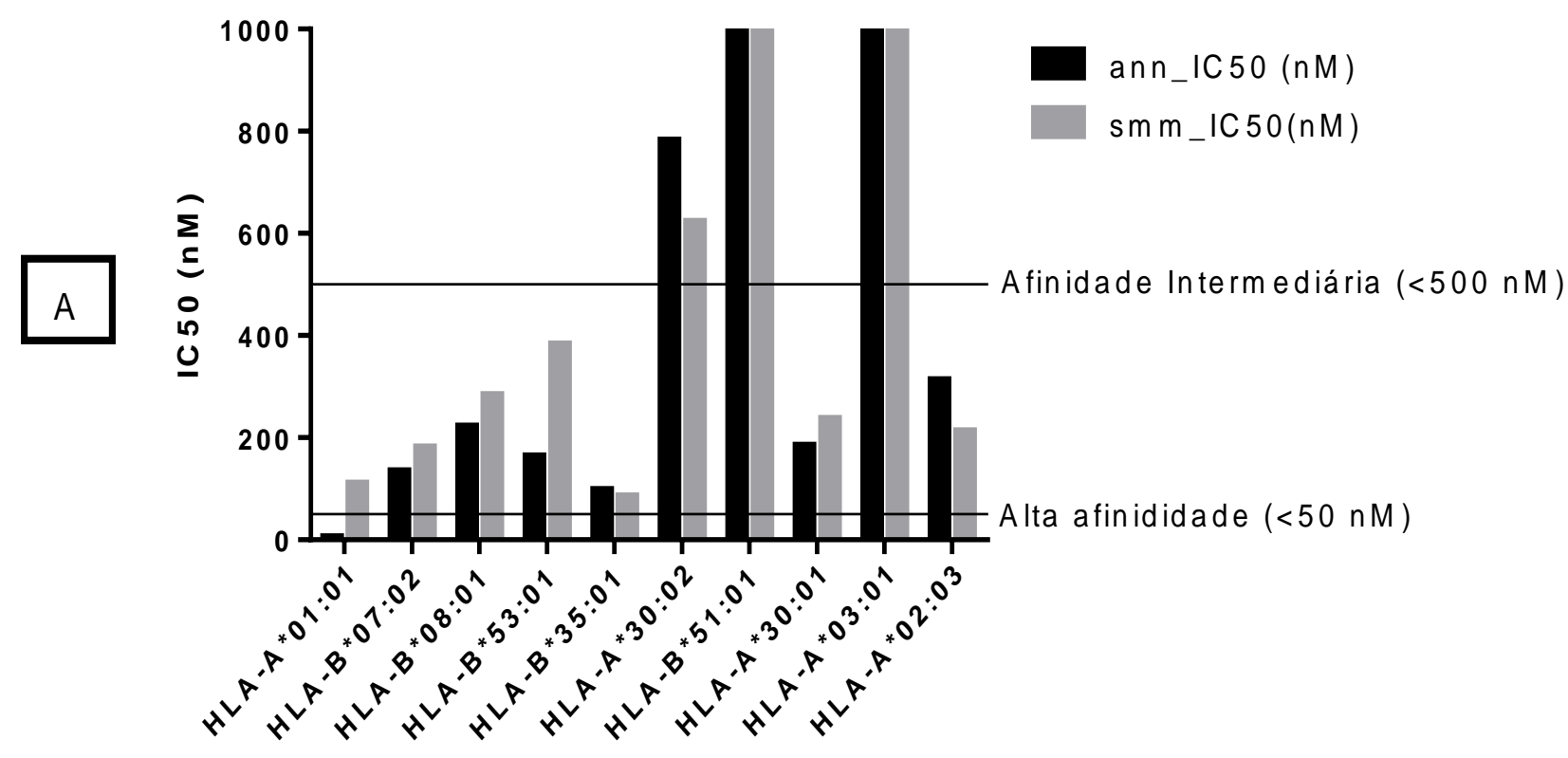

Zika MHCI (10aa)

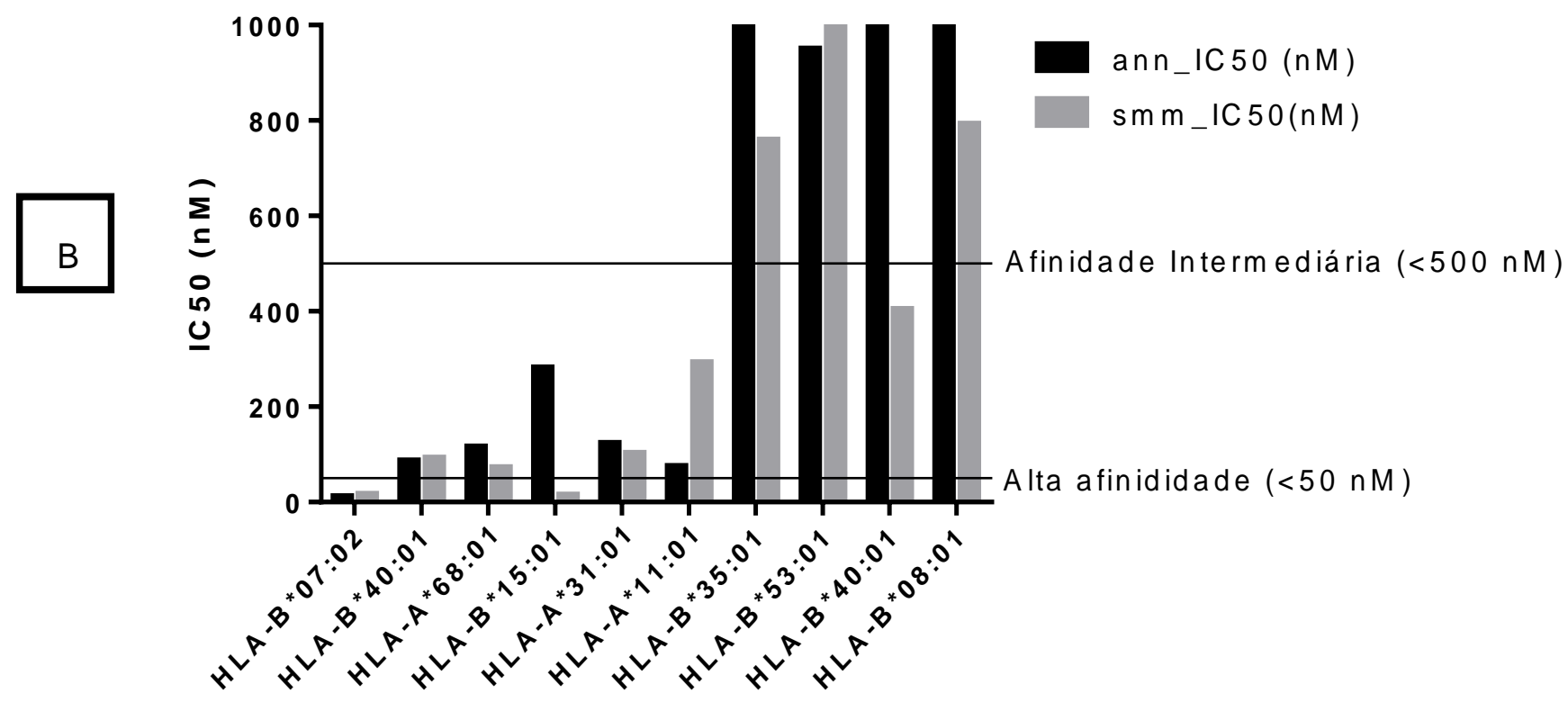


Gráfico 3: Demonstração do Rank Preditivos em IC50nM dos alelos encontrados para o ZIKV-MCHII

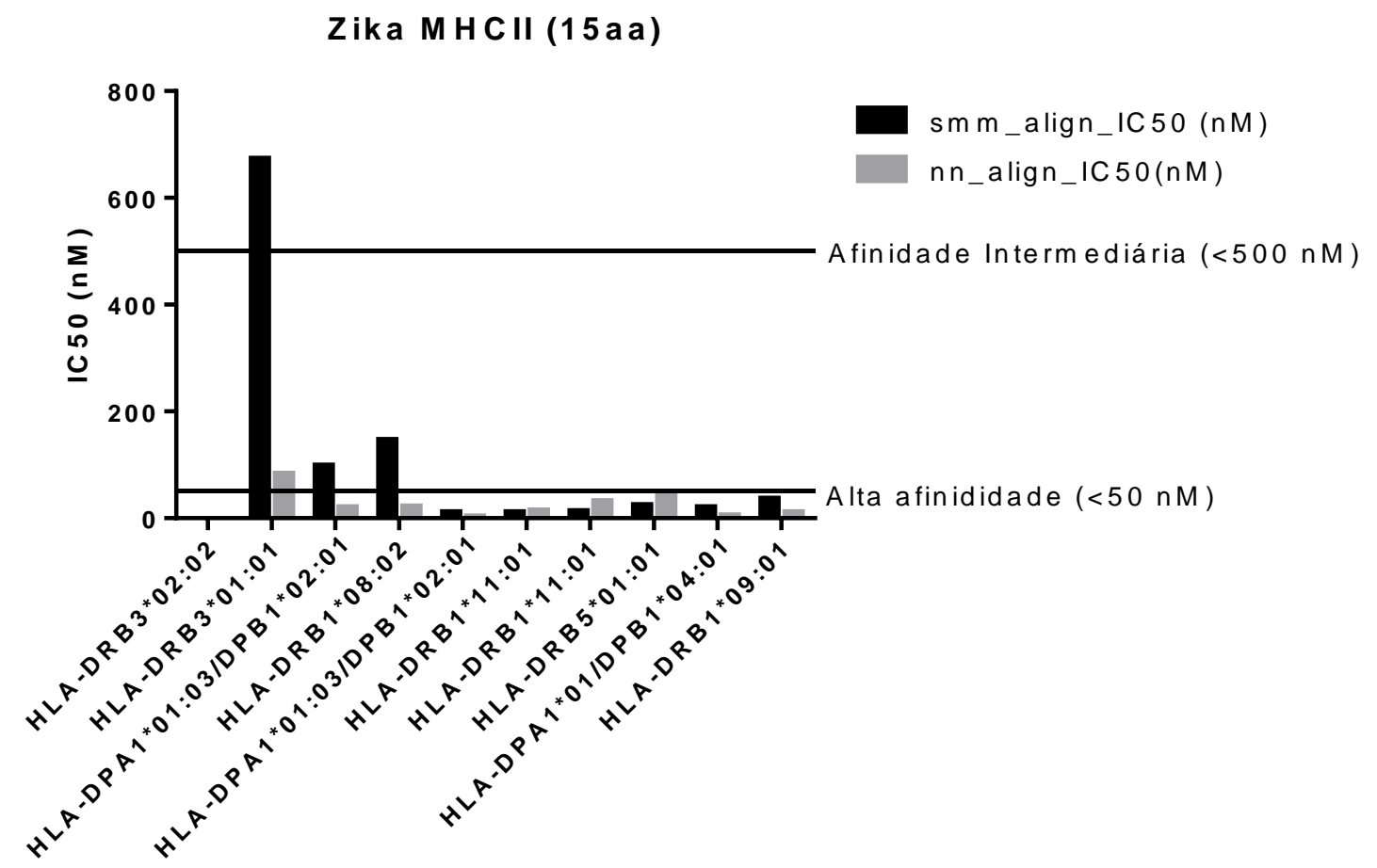

Enquanto alguns dados de predições são quantitativos, existem desvios sistemáticos nos valores experimentais de IC50. Uma correlação mais acurada entre os valores preditivos em IC50 e antigenicidade dos peptídeos estão em processo de atualização e desenvolvimento no banco de dados para uma melhor avaliação, o software também leva em consideração o método de avaliação utilizado, sendo eles o método ANN, o SMM e o Consensus. Os próprios desenvolvedores do sistema afirmam que o método mais adequado de análise é o ANN, por ser mais preciso e estar em constante processo de atualização, o que consequentemente limita a quantidade de erros analíticos.

Além dos valores preditivos em IC50, existe o rank percentual, que é gerado pela comparação entre peptídeos IC50 contra um conjunto aleatório de peptídeos do banco de dados do Swissprot. Quanto menor o número no gráfico comparativo do rank percentual maior é a afinidade do peptídeo. Os Gráficos 4,5,6 demostram a comparação dentro do rank percentual dos alelos encontrados, juntamente com a quantidade de aminoácidos em cada peptídeo, é possível avaliar tanto por gráfico, quanto por tabela. 
Gráfico 1: Demonstração do Rank Percentual dos alelos encontrados para o CHIKV$\mathrm{MCHI}$

Chikungunya M HCI (9aa)

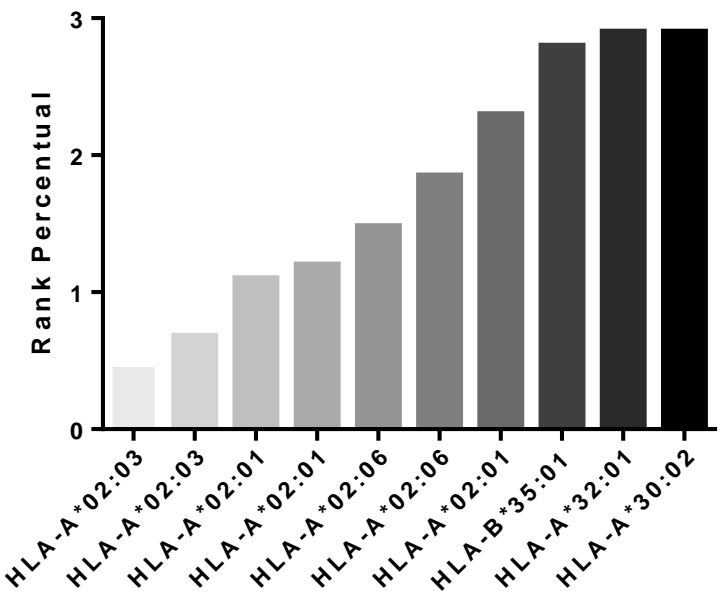

Chikungunya MHCI (10aa)

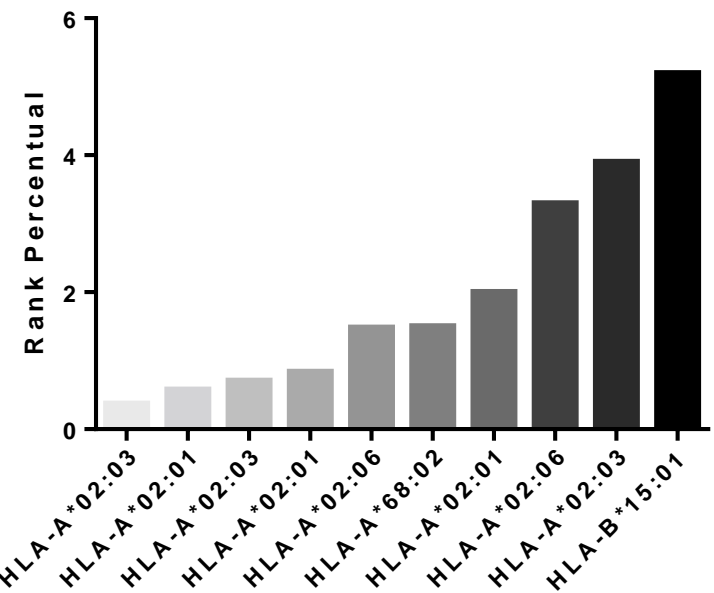

Gráfico 2: Demonstração do Rank Percentual dos epítopos encontrados para o ZIKV$\mathrm{MCHI}$

Zika M HCI (9aa)

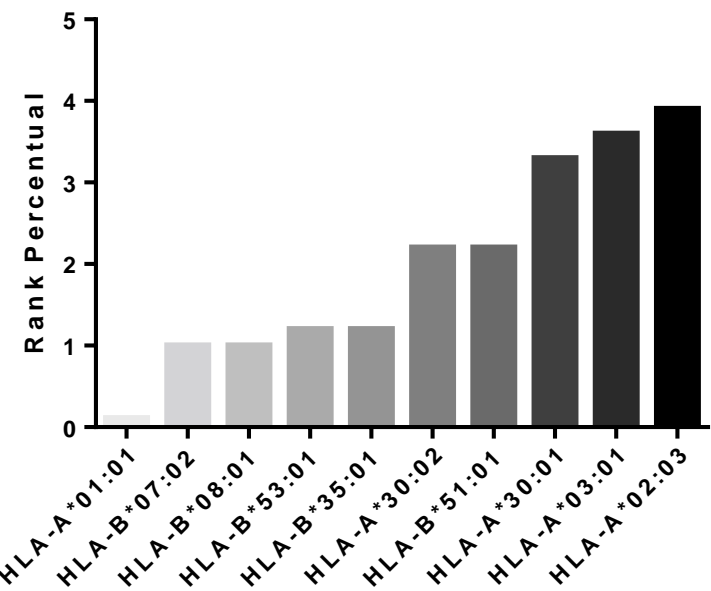

Zika MHCI (10aa)

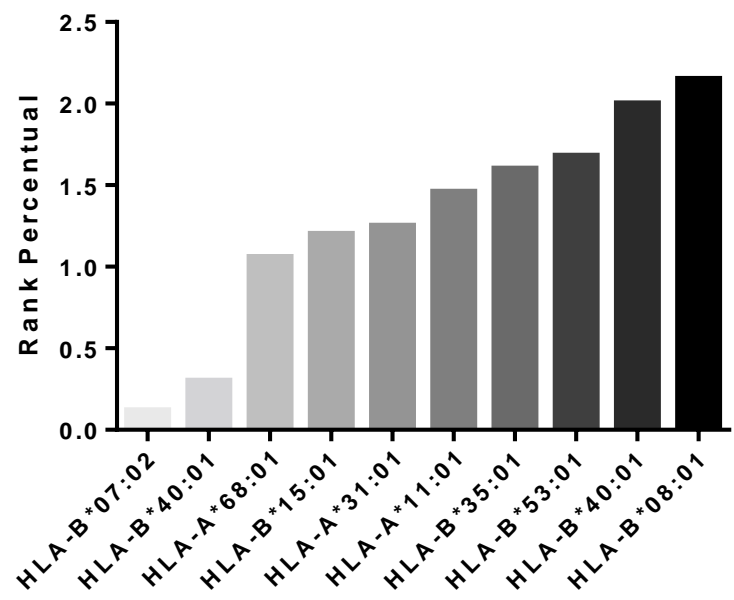


Gráfico 3: Demonstração do Rank Percentual dos epítopos encontrados para o CHIKV-MCHII

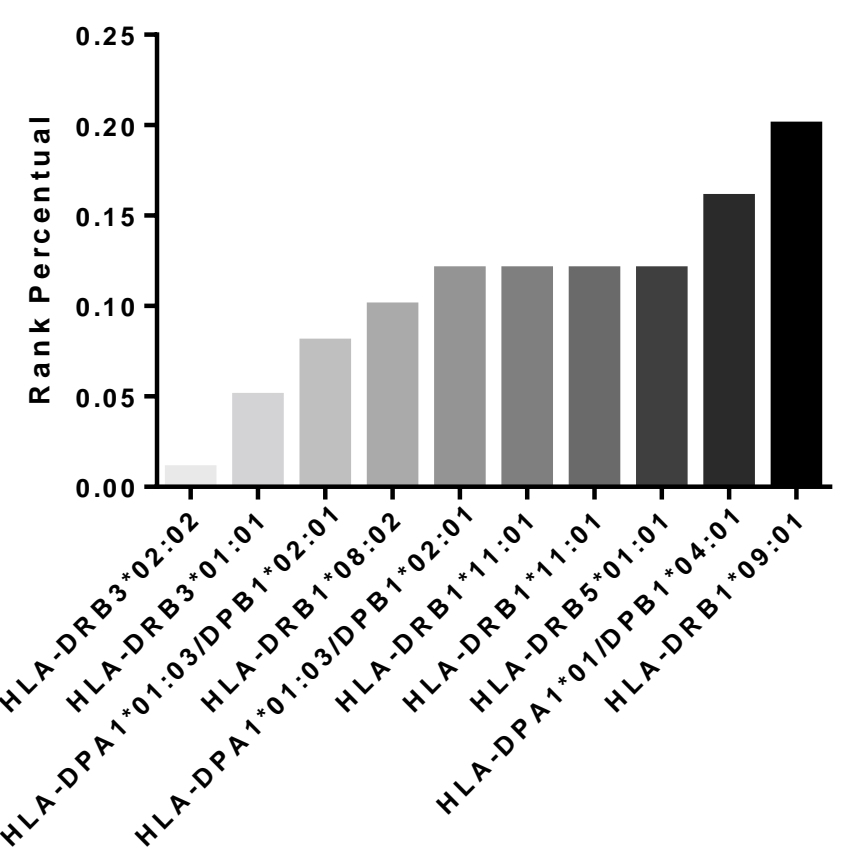

Abbas, Lichtman \& Pillai (2015) explicam que a força de ligação entre um único local de combinação de um anticorpo e um epítopo antigênico é chamada de afinidade do anticorpo. A afinidade é comumente representada por uma constante de dissociação $(K d)$ que indica a facilidade de separação de um complexo antígenoanticorpo em seus constituintes. Um $K d$ menor indica uma interação afinidade maior ou mais forte porque uma menor concentração tanto de antígenos quanto de anticorpo é necessária para a formação do complexo. Os bancos de dados de epítopos também levam consideração esse conceito em relação a delimitação do rank de alelos preditivos, já o rank percentual de alelos leva em consideração a analise quantitativa de dois bancos de dados, por isso seus valores são relativamente menores, o que não exclui a utilização do conceito de dissociação e afinidade que os epítopos prédispostos devem ter. 


\section{CONCLUSÕES FINAIS}

A bioinformática é uma área interdisciplinar, muito recente e promissora no campo da pesquisa. Diversos dados atualmente são processados utilizando a bioinformática economizando tempo e recurso. Atualmente diversos bancos de dados e softwares estão disponíveis gratuitamente para auxiliar e facilitar diversas áreas de pesquisa.

O objetivo do deste projeto foi pesquisar possíveis epítopos dos vírus Zika e Chikungunya in silico que podem ser utilizados para fabricação de imunoterápicos de relevância clínica, analisar epítopos a partir das sequências de possíveis antígenos do vírus Zika e Chikungunya, modelar estruturas terciárias dos antígenos dos dois vírus, utilizando modelagem ab initio ou proteínas já moldadas no PDB e validar as estruturas terciárias modeladas dos antígenos dos vírus Zika e Chikungunya.

O trabalho trouxe resultados positivos in silico, entretanto se faz necessário um estudo in vitro e in vivo com os epítopos selecionados. O estudo in vitro, é importante para averiguar se realmente há a interação entre o epítopo e as células de defesa e se as células de defesa conseguem produzir MHC viável com o epítopo. Já o estudo in vivo é necessário para ver se o epítopo gerará uma resposta imune no hospedeiro e se essa resposta imune será viável para produzir células de memoria e acabar imunizando a pessoa contra o vírus.

É valido ressaltar que a relevância do presente trabalho se dá pelo devido norteamento que ele gera em relação aos possíveis epítopos que poderão ser utilizados para produção e seleção de imunoterápicos. Existem diversos outros métodos de predição de epítopos, desde os mais simples aos mais complexos, entretanto a predição de epítopos via bioinformática economiza tempo e recurso, além de comparar estudos já realizados para gerar dados mais concretos para novos estudos na área da imunobioinformática. 


\section{REFERÊNCIAS}

ABBAS, A. K.; LICHTMAN, A. H.; PILLAI, S. H. I. V. Imunologia Celular e Molecular. 8. ed. Rio de Janeiro: Elsevier, 2015.

AKEY, D.L. et al. Flavivirus NS1 structures reveal surfaces for associations with membranes and the immune system. Science, New York, v. 343, n, 6173, p.881-885, fev. 2014.

AVILA, R.A.M. Predição de epítopos descontínuos ou conformacionais em proteínas através da bioinformática estrutural. 2013. Dissertação (Doutorado em Bioinformática) - Instituto de Ciências Biológicas, Universidade federal de Minas Gerais, Belo Horizonte, 2013.

BALASUBRAMANIAN, S. et al TIM family proteins promote the lysosomal degradation of the nuclear receptor NUR77. Science Signaling. 2013, v. 5, n. 254, ra.90, 2012.

BREVE, A.L.S. Predição In Silico de Epítopos de Microrganismos com Identidade a Auto Antígenos Humanos. 2010. Dissertação (Mestrado em Genética) - Faculdade de Medicina de Ribeirão Preto, Universidade de São Paulo, Ribeirão Preto, 2009.

BRITO M. N; DONATO M. A. M. VÍrus Zika e o sistema nervoso central: uma revisão de literatura. Cadernos de Graduação: Ciências Biológicas e da Saúde. v. 3, n. 1, 2017.

BOWEN, J. R. et al. Zika Virus Antagonizes Type I Interferon Responses during Infection of Human Dendritic Cells. Plos Pathogens, v. 13, n. 2, 2017.

COLLINS, M. H. METZ, S.W. Progress and Works in progress: Update on Flavivirus Vaccine Development. Clinical Therapeutics, Princeton, v.3, n.1, p.1-18, Jun. 2017.

DAS. T. JAFFAR-BANDJEE, M.C. HOARAU, J.J. KREJBIC, H. TROTOT, P. DENIZOT M, LEE-PATYUEN, G. et al. Chikungunya fever: CNS infection and pathologies of a reemerging arbovirus. Progress in Neurobiology, Inglaterra, v.91, n.2, p.121-129. Jun, 2010.

DAVIS, C. W. et al. West Nile virus discriminates between DC-SIGN and DC-SIGNR for cellular attachment and infection. Journal of Virology, v. 80, p. 1290-1301, 2006. 
GRUBER, G. E. Anticorpos monoclonais contra o vírus Zika: obtenção e possível uso em diagnóstico e terapia. 2017. Trabalho de Conclusão de Curso. Setor de Ciências Biológicas - Universidade Federal do Paraná, Curitiba.

HAMEL R. et al. Biology of Zika virus infection in human skin cells. Journal of Virology. v. 89, n. 17, 2015.

JUNIOR, J.X.S. Avaliação epidemiológica e genômica do vírus Chikungunya circulante no Rio de Janeiro. Dissertação apresentada ao Programa de Pósgraduação em Patologia Humana para obtenção do grau de mestre. Universidade Federal da Bahia. Salvador, 2019

KOZLOVA, E. VIART, B. DE AVILA, R. FELICORI, L. CHAVEZ-OLORTEGUI, C. Classification epitopes in groups based on their protein family. BMC Bioinformatics. Inglaterra, v.16, n 19. Dez, 2016.

KUNIK, V. OFRAN, Y. The structural basis of antibody-antigen recognition. Front Immunology v.8, n.4. Out. 2013

LONG, F. et al. Cryo-EM structures elucidate neutralizing mechanisms of antichikungunya human monoclonal antibodies with therapeutic activity. Proceedings of the National Academy of Sciences, v. 112, n. 45, p. 13898, 2015.

MASSY E, et al. P133 HLA-ANTIGENS and disease manifestation in a cohort of 600 southern French patients with psoriatic arthritis Annals of the Rheumatic Diseases BMJ Publishing Group Limited, v.77, n.1 p.70 - 71, fev. 2018.

MARÍA, R. R. et al. The Impact of Bioinformatics on Vaccine Design and Development. In: Vaccines. InTech, p 1 - 24. set 2017.

MOYLE, P. M. TOTH, I. An efficient, chemically defined semisynthetic lipid-adjuvanted nanoparticulate vaccine development system. Nanomedicine, v.9, n.7, Fev. 2013.

MURPHY, K. Imunobiologia de Janeway. 8. ed. Porto Alegre: Artmed, 2014.

MURRAY P. R.; ROSENTHAL K. S.; PFALLER M. A. Microbiologia médica. 7. ed. Rio de Janeiro: Elsevier, 2014. 
NUNES, M.R. FARIA, N.R. DE VASCONCELOS, J.M. GOLDING, N. KRAEMER, M.U. DE OLIVEIRA, L.F et al. Emergence and potential for spread of Chikungunya virus in Brazil. BMC Med, England, v.13, n.102, p.1-11, Abr 2015.

OEHLER, E. WATRIN, L. LARRE, P. LEPARC-GOFFART, I. LASTĖRE, S. VALOUR, $F$ et al. Zika virus infection complicated by Guillain-Barre syndrome-case report, French Polynesia, December 2013. Euro Surveill, Sweden, v.19, n.9, Mar, 2014.

PEREIRA, A.S. Mapeamento de Epítopos das proteínas do vírus Zika na interação materno-infantil pelo método de spot synthesis. 2018. Dissertação (Mestrado em Ciências) -Instituto de Ciências Biomédicas -ICB, Universidade de São Paulo, São Paulo.

PIERSON T.C.; GRAHAM B.S. Zika Virus: Immunity and vaccine development. Cell, v. 167, n. 3, 2016.

SHARMA, R. et al. Structure-function insights into chikungunya virus capsid protein: Small molecules targeting capsid hydrophobic pocket. Virology, v. 515, p. 223-234, 2018.

RAPHAEL, I. et al. T cell subsets and their signature cytokines in autoimmune and inflammatory diseases. Cytokine, v. 74, p. 5-17, 2015

RAPLEY, R. WHITEHOUSE, D. Molecular Biology and Biotechnology. Cambridge: The Royale Society of Chemistry, 2015.

REINHOLD, J. M.; LAZZARI, C. R.; LAHONDÈRE, C. Effects of the Environmental Temperature on. Insects, v. 9, n. 4, nov. 2018

RELICH R.F.; LOEFFELHOLZ, M. Zika Virus. Clinics in Laboratory Medicine. v. 37, n. 2, p. 253-267, 2017

REY F. A.; STIASNY K.; HEINZ F. X.; Flavivirus structural heterogeneity: implications for cell entry. Current Opinion in Virology. n. 24, p. 132-139, 2017.

SANLÉS A. F. et al. Functional information stored in the conserved structural RNA Domains of Flavivirus Genomes. Frontiers in Microbiology. v. 8, n. 546, 2017.

SAPPARAPU, Gopal et al. Neutralizing human antibodies prevent Zika virus replication and fetal disease in mice. Nature, v. 540, n. 7633, p. 443, 2016. 
SCHWARTZ, O.; ALBERT, M. L. Biology and pathogenesis of chikungunya virus. Nature Reviews Microbiology, v. 8, p. 491, 2010

SCHWEDE, T; PEITSCH, M. Computacional Structural Biology: Methods and Applications. 1 ed. Singapore: World Scientific Publishing Co., 2008.

SILVA, A.B.R. Aspectos gerais da infecção pelo vírus Zika: Uma Revisão. Monografia apresentada para obtenção do título de bacharel em Biomedicina. Universidade Federal do Rio Grande do Norte. Natal, 2017.

SOLIGNAT, M. et al. Replication cycle of chikungunya: A re-emerging arbovirus. Virology, v. 393, n. 2, p. 183-197, 2009

SONG B. H. et al. Zika virus: History, epidemiology, transmission, and clinical presentation. Journal of Neuroimmunology, v. 308, p. 50-64, 2017.

TANABE, E. L. L. et al. Report of East-Central South African Chikungunya virus genotype during the 2016 outbreak in the Alagoas State, Brazil. Revista do Instituto de Medicina Tropical de São Paulo, v. 60, p. e19, 2018a

TASSANEETRITHEP, B. et al. Dc-sign (CD209) mediates Dengue virus infection of human dendritic cells. The Journal of Experimental Medicine, v. 197, p. 823-829, 2003.

TRIER N.H; HANSEN P.R, HOUEN G. Production and characterization of peptide antibodies. Methods, v.56, n.2, p.136-44, Fev, 2012.

VAN DUIJL-RICHTER, M. K. S. et al. Chikungunya virus fusion properties elucidated by single-particle and bulk approaches. Journal of General Virology, v. 96, n. 8, p. 2122-2132, 2015.

VITA, R.. ZARBSKI, L,. GREenbaum, J. A.. EMAMI, H.. HOOF, I.. SALIMI, N.. DAMLE, R.. SETTE, A.. PETERS, B. The Immune Epitope Database 2.0. Nucleic Acids Research, v.38, p.854-862, 2010.

VOSS, J. E. et al. Glycoprotein organization of Chikungunya virus particles revealed by X-ray crystallography. Nature, v. 468, p. 709, 2010

WEAVER, S. C. et al. Zika virus: history, emergence, biology, and prospects for control. Antiviral Research. v. 130, n. 2016, p. 69-80, 2016. 
WHO (WORLD HEALTH ORGANIZATION) Integrating neglected tropical diseases into global health and development. 4th WHO report on neglected tropical $\begin{array}{ll}\text { diseases. } & 2017 .\end{array}$ WHO (WORLD HEALTH ORGANIZATION) Number of reported cases of Chikungunya fever in the Americas, by country or territory with autochthonous transmission, Epidemiological Week. 2014.

YAP, M. L. et al. Structural studies of Chikungunya virus maturation. Proceedings of the National Academy of Sciences, v. 114, n. 52, p. 13703. May, 2017. 